This item was submitted to Loughborough's Research Repository by the author.

Items in Figshare are protected by copyright, with all rights reserved, unless otherwise indicated.

\title{
Tribo-dynamic analysis of high-speed roller bearings for electrified vehicle powertrains
}

PLEASE CITE THE PUBLISHED VERSION

https://doi.org/10.1016/j.triboint.2020.106675

PUBLISHER

Elsevier

VERSION

AM (Accepted Manuscript)

\section{PUBLISHER STATEMENT}

This paper was accepted for publication in the journal Tribology International and the definitive published version is available at https://doi.org/10.1016/j.triboint.2020.106675.

LICENCE

CC BY-NC-ND 4.0

\section{REPOSITORY RECORD}

Questa, Harry, Mahdi Mohammad-Pour, Stephanos Theodossiades, Colin Garner, Rickie Bewsher, and Guenter Offner. 2020. "Tribo-dynamic Analysis of High-speed Roller Bearings for Electrified Vehicle Powertrains”. Loughborough University. https://hdl.handle.net/2134/12990905.v1. 


\title{
Tribo-Dynamic Analysis of High-Speed Roller Bearings for Electrified Vehicle Powertrains
}

\author{
H. Questa ${ }^{1}$, M. Mohammadpour ${ }^{1}$, S. Theodossiades ${ }^{1}$, C. P. Garner ${ }^{1}$, S. R. Bewsher ${ }^{2}$, G. Offner ${ }^{2}$ \\ ${ }^{1}$ Wolfson School of Mechanical, Electrical and Manufacturing Engineering, Loughborough University, \\ Loughborough, LE11 3TU, United Kingdom \\ ${ }^{2}$ AVL List GmbH, Graz, Austria \\ *Corresponding author: h.questa@lboro.ac.uk
}

\begin{abstract}
Roller bearings are critical components in electrified powertrains. At high speeds, the critical role of the elastohydrodynamic lubrication (EHL) cannot be ignored, necessitating a tribo-dynamic analysis. This paper investigates the behaviour of roller bearings under operating conditions present in high-speed electrified powertrains. The bearing motion is obtained experimentally using a novel experimental rig. The bearing centre's orbital motion is acquired from the experiment and used as the boundary conditions for tribological analysis. Results reveal that the EHL film thickness increases from 0.2 to 1.9 micrometres across a speed range of $0-15000 \mathrm{rpm}$. A comparison with conventional dry contact analysis shows that roller load can be underestimated if the lubricant film is neglected in the roller-race contact deformation.
\end{abstract}

\section{Keywords:}

Electrified Powertrain, Roller Bearings, EHL, Dynamics, Efficiency

Nomenclature:

$\begin{array}{cl}A_{a} & \text { Asperity apparent contact area }\left(\mathrm{m}^{2}\right) \\ A & \text { Apparent contact area }\left(\mathrm{m}^{2}\right) \\ a & \text { Acceleration }\left(\mathrm{m} \cdot \mathrm{s}^{-2}\right) \\ b & \text { Half-length of the contact }(\mathrm{mm}) \\ \mathrm{C} & \text { Radial clearance }(\mu \mathrm{m}) \\ c^{\prime} & \text { Solid specific heat capacity }\left(\mathrm{J} \cdot \mathrm{kg}^{-1} \cdot \mathrm{K}^{-1}\right) \\ D_{r} & \text { Diameter of roller }(\mathrm{mm}) \\ D_{p} & \text { Pitch diameter }(\mathrm{mm}) \\ E_{r} & \text { Equivalent }(\text { reduced) elastic modulus }(\mathrm{Pa}) \\ F_{x} & \text { Radial load in x-direction }(\mathrm{N})\end{array}$




\begin{tabular}{|c|c|}
\hline$F_{y}$ & Radial load in $\mathrm{y}$-direction $(\mathrm{N})$ \\
\hline$f$ & Total friction $(\mathrm{N})$ \\
\hline$f_{b}$ & Boundary friction $(\mathrm{N})$ \\
\hline$f_{v}$ & Viscous friction $(\mathrm{N})$ \\
\hline$f_{b p i}$ & Ball Pass Frequency of Outer Race $(\mathrm{Hz})$ \\
\hline$f_{b p o}$ & Ball Pass Frequency of Inner Race $(\mathrm{Hz})$ \\
\hline$f_{\text {shaft }}$ & Shaft Rotational Frequency $(\mathrm{Hz})$ \\
\hline$G^{*}$ & Dimensionless equivalent geometry (-) \\
\hline$h_{c}$ & Central film thickness $(\mathrm{m})$ \\
\hline$k$ & Stiffness $\left(\mathrm{Nm}^{-1}\right)$ \\
\hline$K$ & Lubricant thermal conductivity $\left(\mathrm{W} \cdot \mathrm{m}^{-1} \cdot \mathrm{K}^{-1}\right)$ \\
\hline$L$ & Roller length (mm) \\
\hline$n$ & Exponent of localized deflection (-) \\
\hline $\mathrm{N}$ & Number of rolling elements (-) \\
\hline$p$ & Contact pressure $(\mathrm{Pa})$ \\
\hline $\bar{p}$ & Average pressure at the apparent contact $(\mathrm{Pa})$ \\
\hline$r_{i n}$ & Radius of inner race $(\mathrm{mm})$ \\
\hline$R_{z x}$ & Equivalent radius of contact (mm) \\
\hline$u$ & Speed of entraining motion $\left(\mathrm{m} \cdot \mathrm{s}^{-1}\right)$ \\
\hline$U^{*}$ & Dimensionless speed parameter (-) \\
\hline$v$ & Velocity $\left(\mathrm{m} \cdot \mathrm{s}^{-1}\right)$ \\
\hline$W$ & Contact load $(\mathrm{N})$ \\
\hline$W^{*}$ & Dimensionless load parameter (-) \\
\hline$W_{a}$ & Asperity load $(\mathrm{N})$ \\
\hline$x$ & Displacement in $\mathrm{x}$-direction (m) \\
\hline$x_{c}$ & Conjunction x-coordinate (-) \\
\hline$y$ & Displacement in y-direction (m) \\
\hline$y_{c}$ & Conjunction y-coordinate (-) \\
\hline
\end{tabular}

\section{Greek Symbols:}

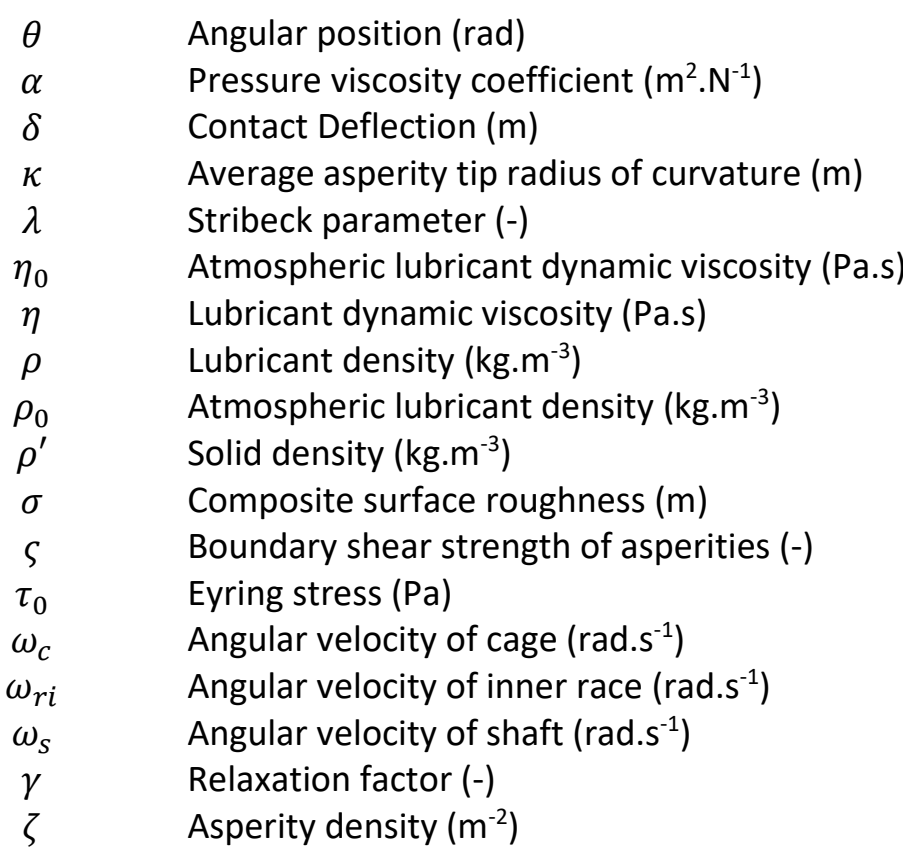




\section{Introduction}

Due to shifts in emissions regulations, technology and customer attitudes, electric and hybrid electric vehicles are estimated to have a global market share of $48 \%$ by 2030 [1]. The electric motors used in these powertrains are often lightweight to meet packaging and mass constraints and operate at high rotational speeds to achieve power requirements. This style of powertrain architecture involves high-speed bearing operation in both the motor and transmission. The associated performance characteristics of these bearings such as friction and wear [2], thermal stability and generated vibration and noise must be modelled accurately at the development stage to ensure system level success [3].

To fully understand bearing performance under the conditions present in modern electrified vehicles, a multiphysics approach comprising dynamics and tribology of the system at high speeds is required. Since load is transmitted through the bearing, for example via a gear tooth load during a meshing cycle, the rolling elements undergo complex oscillatory motion that results in impact at lubricated contacts between the rollers and races. This dynamic behaviour of the bearing prevails the force transmission from the excitation source to the housing and the structure. Hence, noise, vibration and harshness (NVH) refinement is affected. It also dictates the working conditions for the tribological contacts. The dynamic behaviour itself is affected by the tribological phenomena at the lubricated conjunctions via introduced frictional dissipation and potential stiffness [4] [5] and damping effects of the lubricant film. Therefore, a coupled tribo-dynamic methodology needs to be established for more accurately capturing the system's behaviour.

Accounting for lubricant film thickness distribution at the roller-race conjunction at each step of a dynamic analysis is a time-consuming simulation. Previous studies have de-coupled the analysis into two stages. Bearing centre displacement is obtained through solving equations of motion, utilizing dry-Hertzian contact mechanics to calculate the roller-raceway load-deflection relationship. Extrapolated film formulae are then employed to calculate the film thickness at the contact based on the reaction force [6]. This does not consider implicitly the effect of the lubricant film on the prevailing bearing motion and load which is hence underestimated. Rahnejat and Gohar [7] overcame this by using extrapolated central film formulae to account for film thickness as well as deflection at the contact. More realistic bearing vibration amplitudes were reported; however the extrapolated film formulae are somewhat limited to the range of operating parameters used in original simulations. Film shape and pressure profile at the contact, as well as thermal and sub-surface stress analysis could not be performed without full numerical EHL analysis. To determine tribological contact conditions, Mohammadpour et al. [8] utilised a full numerical elastohydrodynamic analysis explicitly. The abovementioned models were limited to low operating speeds and did not account for the flexibility of the system, which is crucial for high-speed conditions. 
The work presented in this study investigates the tribo-dynamic behaviour of rolling element bearings under high-speed conditions which are representative of modern electrified vehicle applications. Considering the necessity of conducting a multi-physics study, the methodology follows the approach conducted by Mohammadpour et al. [8]; however, the motion of the bearing is obtained experimentally rather than numerically. This allows the consideration of detailed and realistic dynamic behaviour. In this method, the bearing centre's orbital motion is obtained from the component level experiment as the boundary conditions for the tribological analysis. The contact load, film thickness, viscous and boundary friction as well as the EHL pressure and film thickness distributions are then obtained using an implicit tribological model and an explicit 1-dimensional numerical EHL model. This approach addresses the need for a dynamic model of the bearing, removing the associated numerical uncertainty. More importantly, it allows the capture and understanding of the tribological behaviour of the bearing lubricated conjunctions under modern electrified powertrain operating conditions. To simulate these conditions, a novel experimental rig was developed that was able to provide static and dynamic radial loads to a shaft-bearing system up to rotational speeds of $32000 \mathrm{rpm}$, far in excess of similar component level rigs previously reported [9] [10] [11]. Such an approach, combining the experimental measurement of the bearing motion and the numerical simulation of tribological contacts under high-speed conditions has not been previously reported in the literature, to the authors' knowledge.

The significance of this conducted research is that it investigates a new range of bearing working conditions at high speeds from a tribological perspective. It improves the understanding of the governing regimes of lubrication, range of tribological quantities such as film thickness and pressure as well as interaction of tribological behaviour with dynamics of the system. The deeper understanding of these matters will support more objective development of these modern powertrains in future to enhance their efficiency, durability and NVH refinement. The acquired knowledge will also guide future developments of predictive numerical methodologies by understanding the interaction of tribology and dynamics and the significance of considering or neglecting this link.

\section{Methodology}

2.1 Overall workflow: To obtain the film thickness at the roller-race contact, the load on each roller must be calculated implicitly based on the contact deflection. This is obtained conventionally from a dynamic model by solving the equations of motion, but these are currently lacking the required in-depth physics such as system flexibility, flexibility of races and thermal effects [12] [13] [14] [15]. To circumvent the need for a complex flexible dynamic model and to capture real behaviour of a bearing under test, displacement of the bearing centre and hence contact deflection is captured from experimental test results. 
An experimental test rig is used to obtain the relative displacement between the inner and outer bearing races. Then, using the Hertzian load-deflection relationship and accounting for the lubricant film thickness, load on an individual roller is found at each instantaneous position around the bearing centre through a speed sweep of $0-15000 \mathrm{rpm}$. An implicit analytical tribological model is used which calculates the film thickness at the contact. This loop is iterated to account for the tribo-dynamic coupling. After the experimentally informed implicit tribo-dynamic model is solved, load and speed values at specific rotational velocities are used within an explicit numerical EHL model to calculate film thickness and pressure distribution across the contact. The flow diagram in Figure 1 illustrates the methodology used. Interactions between each stage will be explained in subsequent sections.

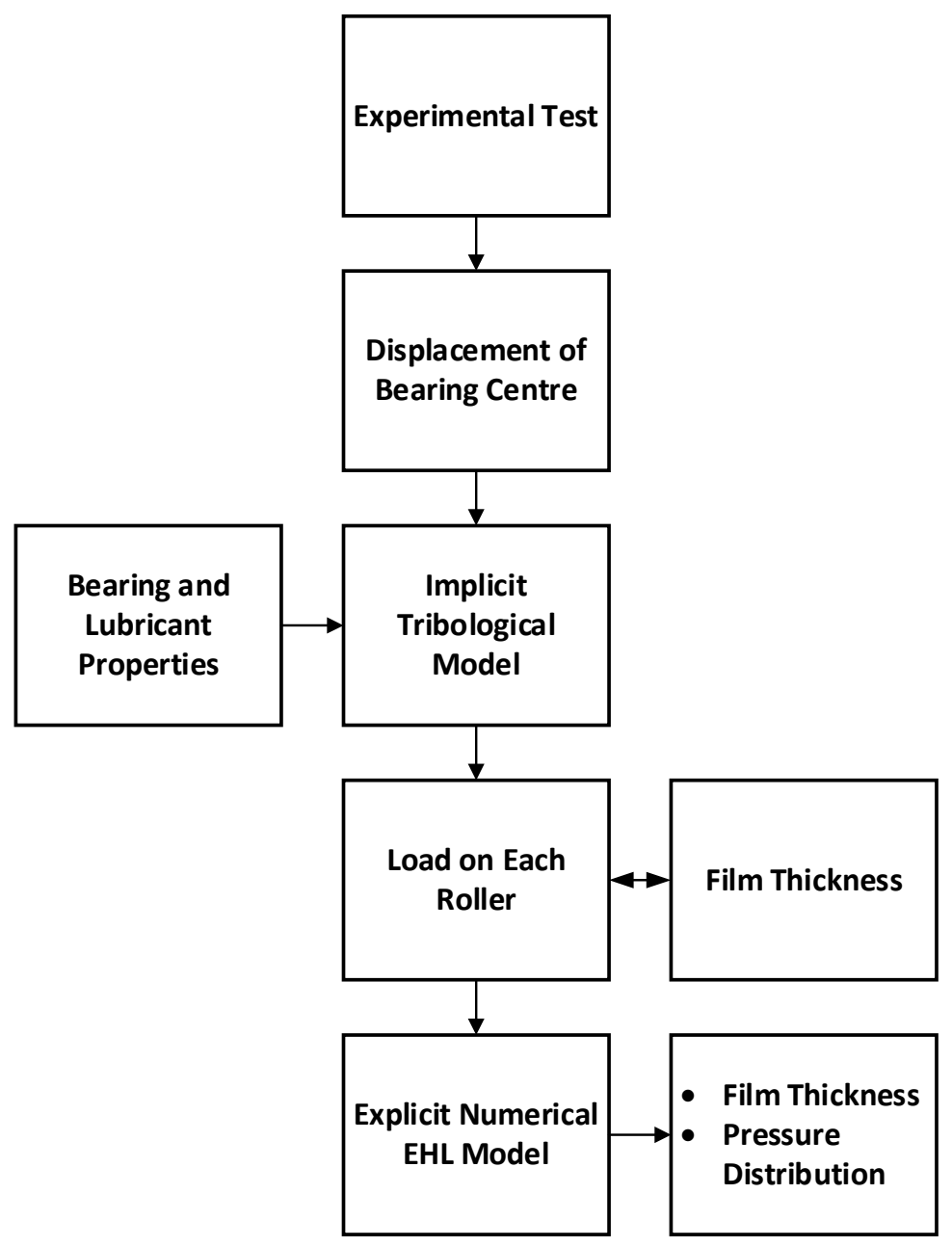

Figure 1 - Methodology overview

The rollers within a bearing carry an instantaneous share of the overall load applied to the bearing [16]. Deviation of the supported shaft centre from its nominal geometric centre results in a loaded region of the bearing. In the conjunction between the bearing roller and race, the non-conformal nature of contact generates very high pressures when under load. This causes local surface deformation and an increase in lubricant viscosity, resulting in EHL film formation [17] [18]. Emerging clearances in unloaded regions of the 
bearing results, which can cause the roller-to-race contact to deviate from the EHL regime towards the hydrodynamic regime, resulting in sliding and roller-cage collisions [8]. Hence, the contact may go through different regimes of lubrication throughout its rotation [19].

Figure 2 shows the cylindrical roller bearing (CRB) in equilibrium position with zero preload or design clearance. Under zero applied radial load, $\mathrm{F}_{0}$, the initial deformation, $\delta_{0}$, and radial clearance, $C_{0}$, between rollers and races are both zero. Due to external force application and system dynamics, an instantaneous radial load, $F$, will displace the inner bearing race from its equilibrium state ( $\Delta x$ and $\Delta y$ ). By analysing an individual roller at its instantaneous angular position, $\theta_{i}$, the resultant displacement of the bearing centre can be used to find deflection at the roller-race contact, $\delta_{i}$. These contact deformations will result in contact forces, $W_{i}$, which act to keep the rollers and races in dynamic equilibrium. The above interpretation is valid considering rigid inner and outer races.

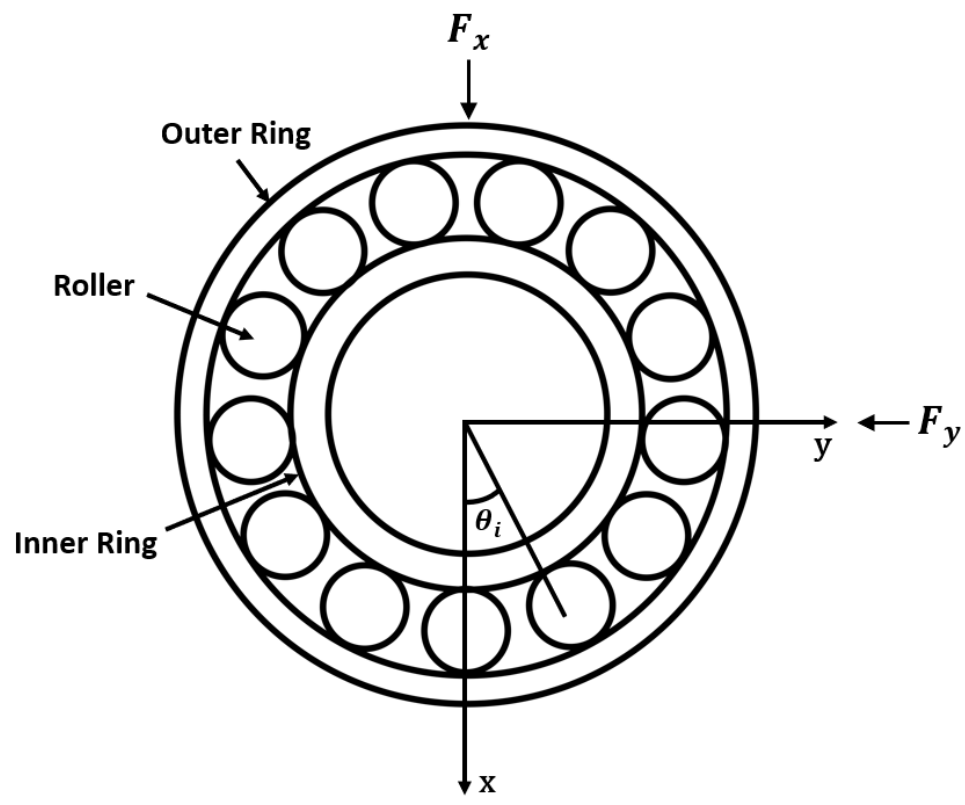

Figure 2 - CRB in equilibrium position

Figure 3 presents the case whereby an instantaneous force is applied to the inner race. This causes deflection of the rollers in the loaded region and clearance or less deflection around the rollers in the unloaded region. The value of the total deflection, $\delta_{i}$ at the inner and outer race corresponds to the component of displacement of the bearing centre at the instantaneous position of that particular roller. In the current study, this value was experimentally measured from the test rig and is used quasi-statically as the boundary condition for the tribological model. It should be noted that in-plane two degrees of freedom motion are analysed in this study which is a valid assumption under dominant radial loading with secondary horizontal motion from the full system dynamics. Misalignment along the length of the rollers is not considered due to the high stiffness of the shaft and bracket, hence a 1-dimensional analysis for EHL is sufficient [20]. 
In the loaded region, the Hertzian load-deflection relationship is used to obtain the resulting instantaneous load on the roller. This value is then used implicitly within an analytical tribological model to calculate contact film thickness for an individual roller as it passes through different angular positions during a speed sweep. An extrapolated film thickness formula is used for this purpose. The calculated film thickness imposes additional deformation at the contact points which itself changes the calculated load (as shown in equation 5). Hence, an iterative approach is required between the force calculation and implicit tribological model. In this part of the workflow, the stiffness and damping of the EHL film is neglected due to its rigid-like stiffness, which is several orders of magnitude higher than the Hertzian contact [21] [22].

a) Loaded Inner Race

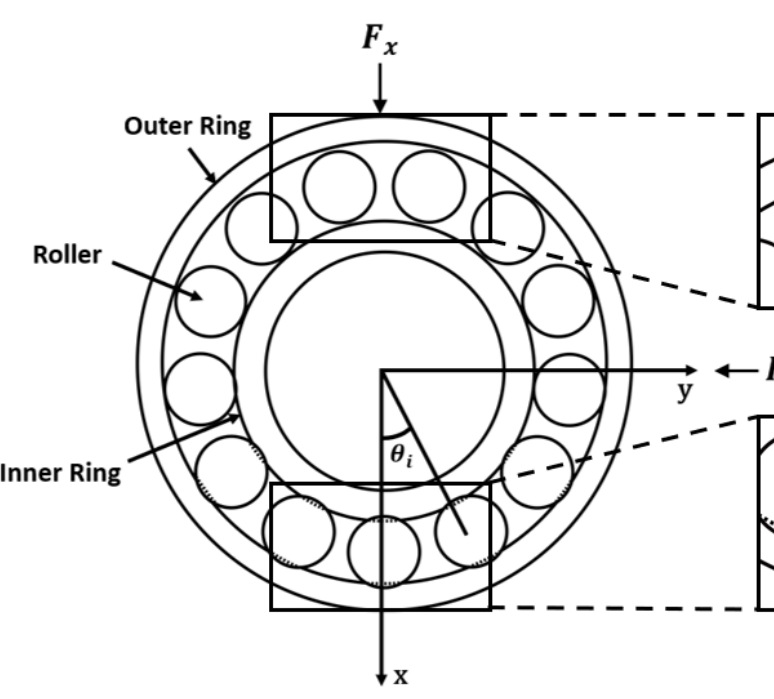

b) Race Separation (top) Race Convergence (bottom) c) Unloaded Clearance (top) Loaded Interference (bottom)

Figure 3-Mutual separation and convergence of inner and outer races: a) Loaded inner race, b) Race separation and convergence, c) Resultant interference and clearance

For in-depth tribological investigations, the numerical solution of the fluid film is essential. This provides the pressure, film thickness and shear distributions in the contact to study the durability and frictional efficiency of the system. In the current study, the load on the roller and contact kinematics obtained from the implicit bearing model is used explicitly in a 1-dimensional elastohydrodynamic model to obtain film thickness and pressure distribution at the contact for specific loading periods through the speed sweep, as is shown in Figure 4. This explicit approach significantly improves the computational efficiency of the model and in principle, maintains the accuracy since only the central value of the film is required in the load calculation. 


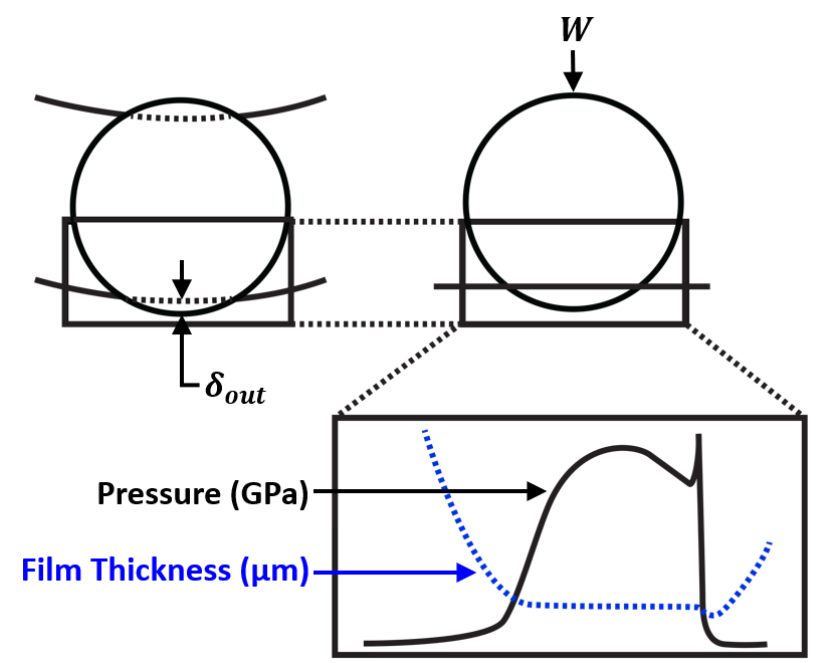

Figure 4 - EHL film thickness and pressure distribution at contact

2.2 Experimental Test Rig: The displacement of the bearing centre governs the conditions at the contact and was found experimentally using a high-speed bearing test rig, originally reported by Walker et al. [23]. A $5 \mathrm{~kW}$ AC synchronous motor, capable of reaching up to $32000 \mathrm{rpm}$ was coupled to a steel shaft that is supported by two bearing brackets. Radial force was transferred to inner bearing race via the shaft using a hinge/arm mechanism and load application device on the shaft. Displacement data were obtained from an instrumented bearing bracket. Figure 5 shows a schematic of the rig.

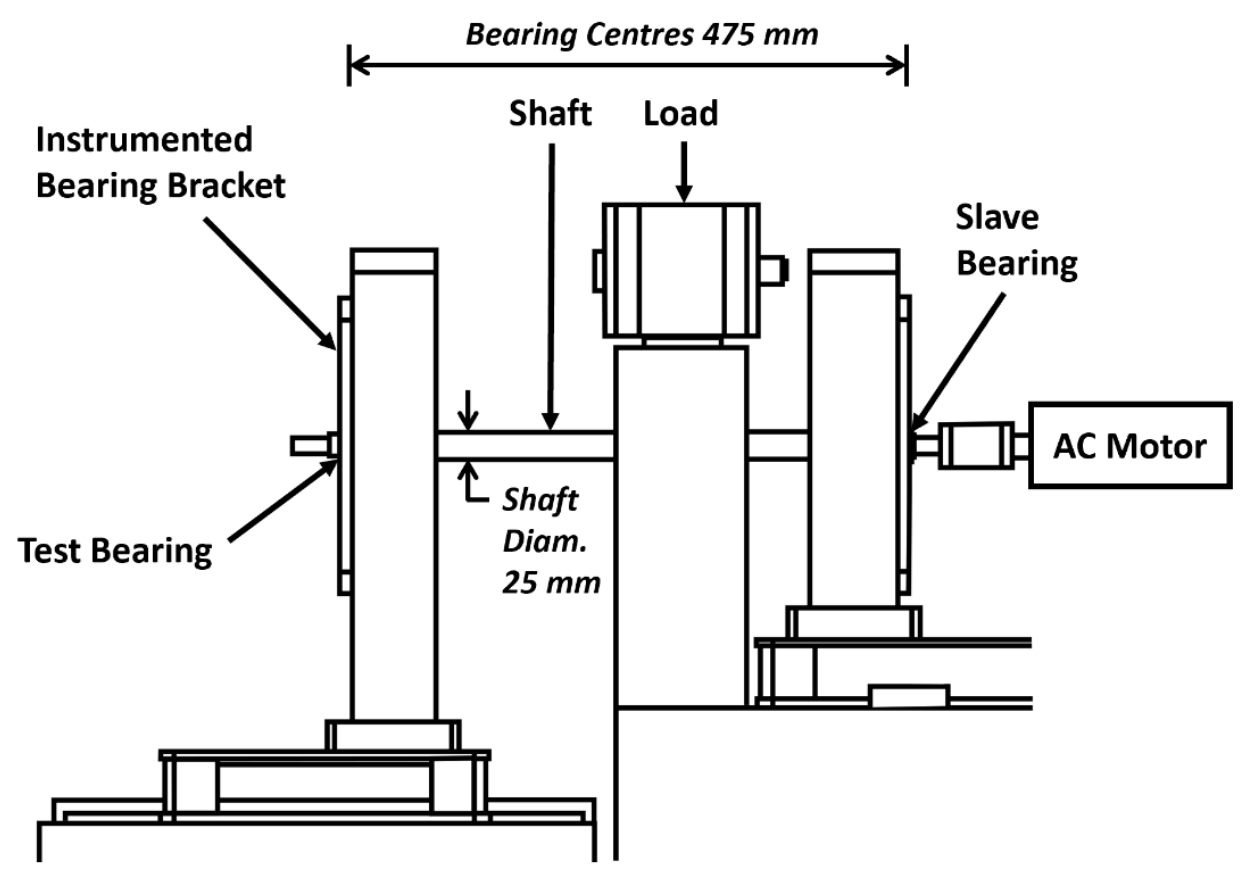

Figure 5 - Experimental rig schematic

The motor control unit was connected to a voltage input, transmitted via an NI cDAQ-9178 USB chassis for optimum resolution of the input voltage. A MATLAB script controlled the voltage ramp over a specified time- 
period and thus the spindle acceleration. In this study, a transient speed sweep was performed from $0-15000 \mathrm{rpm}$ in a $4 \mathrm{~s}$ period, with $750 \mathrm{~N}$ of static radial load applied to the shaft. The bearing under test was a single row cylindrical roller bearing, NU $205 \mathrm{ECP}$, located in an aluminium test bracket that had an extruded bore for instrumentation.

2.3 Instrumentation: The outer surface of the bearing bore was instrumented with two Type 4383 single axis piezo-electric charge accelerometers, with a frequency range of $0.1-8.5 \mathrm{kHz}$ and sensitivity of $3.16 \mathrm{pC} / \mathrm{ms}^{2}$. These measured acceleration of the bracket's bore, corresponding to the outer race of the bearing (Figure 6(a)). Two single beam laser vibrometers measured the displacement of the shaft at the edge of the bearing which corresponds to the displacement of the inner race of the bearing (Figure 6(b)). A dual-beam vibrometer was used to measure the rotational speed of the shaft. All laser vibrometers had a frequency range of $0-10 \mathrm{kHz}$ and maximum speed of $20000 \mathrm{rpm}$.

A program in MATLAB controlled the speed of the shaft through a ramped voltage input. Data was simultaneously acquired from the accelerometers and laser vibrometers through synchronised input channels at a sampling rate of $100 \mathrm{kHz}$. Simultaneous control and data acquisition ensure accurate results between different instrumentation locations.

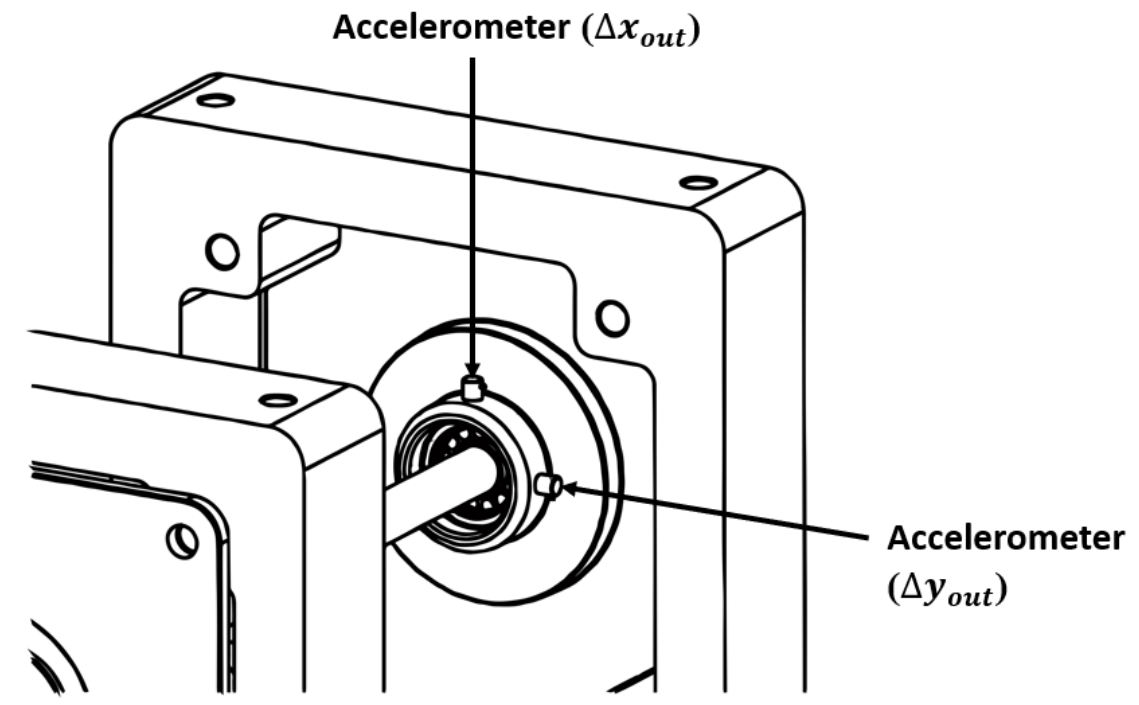

Figure 6(a) - Accelerometer Locations on Test Bracket 


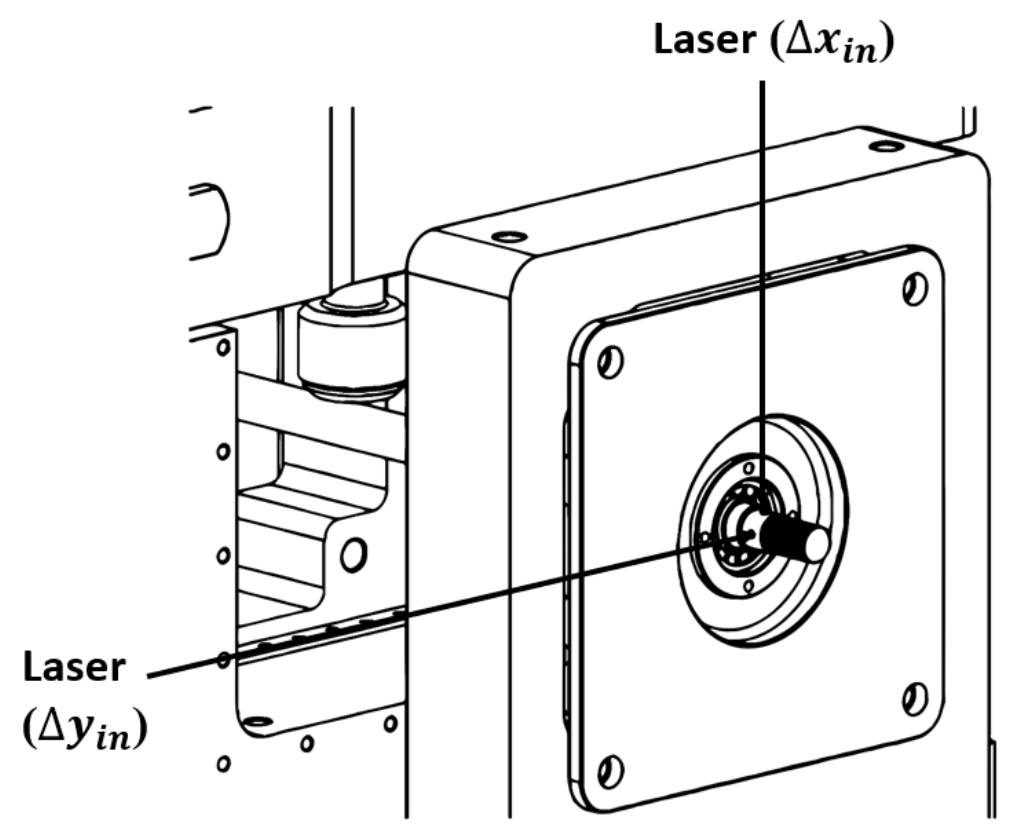

Figure 6(b) - Laser Vibrometer Locations on Shaft

2.4 Signal Processing: The bearing race displacements were obtained from the instrumented bearing using time-domain data from the accelerometers and laser vibrometers. The laser vibrometer directly provided displacement data, whereas the accelerometer data required post-processing of acceleration data. To ascertain the displacement of the bearing bore and thus outer bearing race, the accelerometer results were integrated twice:

$$
\begin{aligned}
& v_{\text {out }}(t)=v_{0, \text { out }}+\int_{0}^{t} a_{\text {out }} d t \\
& x_{\text {out }}(t)=x_{0, \text { out }}+\int_{0}^{t} v_{\text {out }} d t
\end{aligned}
$$

As this double integration amplifies non-linearities in the original signal, it requires pre-processing [24]. Low frequency drift is removed from the unfiltered time-domain data by applying a linear fit to the data and then removing the trend from it.

To extract the frequency content of the speed ramp, waterfall plots were generated using the accelerometer and laser vibrometer data. Short-time fast-Fourier transform (STFFT) was used, with data windows of six shaft rotations at each $100 \mathrm{rpm}$ increment. The resulting signal was then filtered using a Butterworth bandpass filter for a frequency range of $70-10000 \mathrm{~Hz}$ to remove the high amplitude low frequency noise that was inherent to the equipment setup. The filter used $3 \mathrm{~dB}$ of passband ripple and $7 \mathrm{~dB}$ attenuation in the stopbands, which were set at $35-12500 \mathrm{~Hz}$. 
The relative displacement of the bearing centre could then be obtained from the relative displacement between the shaft (measured using the single beam laser vibrometer) and bearing bore:

$$
\begin{aligned}
& \Delta x=\Delta x_{\text {in }}-\Delta x_{\text {out }} \\
& \Delta y=\Delta y_{\text {in }}-\Delta y_{\text {out }}
\end{aligned}
$$

where $\Delta x_{\text {in }}$ and $\Delta x_{\text {out }}$ correspond to the displacements of the shaft and bearing bore respectively.

2.5 Contact Mechanics of the Roller-Race Conjunction: The contact between roller and race is modelled as an elastic deformation between an equivalent finite length elastic cylinder and rigid plate. This assumption is realistic under the conditions of an EHL contact. The contact force on an individual roller at each instantaneous position, $W_{i}$, is obtained from the Hertzian load-deflection relationship:

$$
W_{i}=k \delta_{i}^{n}
$$

where $k$ is the Hertzian contact stiffness non-linearity between a rolling element and the inner or outer raceway groove. For the case of rolling element bearings, the exponent of localised deflection, $n$, is equal to 10/9 [25]. The contact deflection of a roller relative to the race, $\delta_{i}$, is due to the normal dynamic motion (i.e. the local mutual convergence) of the inner and outer bearing races, contribution of lubricant film thickness and any additional clearance or interference fit [8]. This is expressed as:

$$
\delta_{i}=2\left(h_{c, i}-C\right)+x \cos \left(\theta_{i}\right)+y \sin \left(\theta_{i}\right)
$$

where $C$ is the local radial clearance, and $x$ and $y$ are the displacement components of the inner bearing race from its geometric centre. This normal approach between both races is the sum of the total deformation of the rollers and both races [26], hence:

$$
\delta_{i}=\delta_{i, \text { in }}+\delta_{i, \text { out }}
$$

The equilibrium of forces in a system of stiffnesses in series is therefore:

$$
W_{i}=W_{i, \text { out }}=W_{i, \text { in }}
$$

To find the individual deflection of each contact due to differences in contact stiffness, the following relationship is used:

$$
\delta_{i, \text { in }}{ }^{n} k_{i}=\delta_{i, \text { out }}{ }^{n} k_{\text {out }}
$$


The deflection value at each contact based on the total deflection and relationship between contact stiffness is then found from Equation (6) and (8) to give:

$$
\delta_{i, \text { out }}=\frac{\delta_{i}}{\left(\frac{k_{\text {out }}}{k_{\text {in }}}\right)^{\frac{1}{n}}+1}
$$

The normal stiffness of the inner and outer races differs due to their geometry. To calculate the stiffness at each contact, the following equation is used:

$$
\delta=\frac{F}{\pi E_{r} L}\left[\ln \left(\frac{4 \pi E_{r} R_{z x} L}{F}\right)-1\right]
$$

The deflection for a range of loads is calculated based on the geometry and material properties at the inner and outer race contacts. This non-linear relationship is numerically obtained and then curve fitted and represented by a power function in the form $F=a \delta^{b}$, with $b=10 / 9$ and $a$ representing the contact stiffness. Individual contact stiffness and deflection at the inner and outer race contacts is then found. The overall contact stiffness, $K_{i, t o t a l}$, is given by:

$$
K_{i, \text { total }}=\frac{1}{\left(\frac{1}{K_{i, \text { in }}}\right)+\left(\frac{1}{K_{i, \text { out }}}\right)}
$$

where $K_{i, \text { in }}$ and $K_{i, \text { out }}$ are the stiffnesses of the inner and outer race contacts respectively.

2.6 Implicit Tribological Model: A stepwise solution was performed on an individual roller as it passes through each angular position. The roller bearing and bracket tolerances are such that the internal clearance is $0 \mu \mathrm{m}$ between roller and race. This means that in an unloaded state, there is no deflection of elements or raceway. It also means that displacement in positive $x-y$ corresponds to the same total magnitude of deflection of roller and race contact. For each time step, the bearing is first assumed to be in equilibrium position, and film thickness is assumed to be $0 \mu \mathrm{m}$. The deflection of the bearing is calculated under these conditions and is therefore a function of the relative displacement between inner and outer bearing races. With deflection at the time step calculated, the resultant lubricant regime and subsequent analytical solutions can be performed based on the following three conditions:

a) $\delta=0$ indicates a film of $0 \mu \mathrm{m}$ and no load.

b) $\delta<0$ indicates complete separation of the roller and race. In this instance, the lubricant is assumed to fill the separation gap, with the film thickness value equalling the magnitude of the separation: 


$$
h_{i}=\left|\delta_{i}\right|
$$

Under this condition, the lubrication is in the hydrodynamic regime. The hydrodynamic lubricant reaction load was derived by Rahnejat [27], and is given by:

$$
W_{i}=\frac{2 b u_{i} \eta_{0} R_{z x}}{h_{i}}
$$

where $b$ is the half length of the contact, $u$ is the speed of lubricant entrainment into the contact, $\eta_{0}$ is the lubricant viscosity, $R_{z x}$ is the reduced radius of the roller and race and $h$ is lubricant film thickness.

c) $\delta>0$ indicates deflection at the roller-race contact. This means that contact pressure is sufficiently high for the lubrication regime to be elastohydrodynamic. For the elastohydrodynamic regime, an iterative process is performed to solve film thickness. This is due to the contribution of EHL film towards deformation and consequently the load in the contact.

The cylindrical roller and race contacts are modelled by an equivalent rigid roller against a semi-infinite elastic half space of equivalent elastic modulus, $E_{r}$. The extrapolated central film thickness for a line contact is therefore obtained [28] from:

$$
h_{c}=R_{z x}\left[3.06 G^{* 0.56} U^{* 0.69} W^{*-0.1}\right]
$$

where the following dimensionless parameters are used:

$$
W^{*}=\frac{W_{i}}{E_{r} R L}, U^{*}=\frac{\eta_{0} U}{E_{r} R}, G^{*}=E_{r} \alpha
$$

where $R$ is the reduced radius of the contact, $L$ is the length of the roller and $u$ is the speed of entraining motion into the contact and $W$ is the contact load. Assuming pure rolling, the speed of entraining motion is given by:

$$
u_{i}=\frac{1}{2}\left(\omega_{c, i}-\omega_{r i, i}\right) r_{i n}
$$

An iterative process is used to calculate load on the roller based on total deflection including lubricant film (back to Eq.5). At each time step where an EHL film is present, the following convergence criteria must be met before the next time step is calculated:

$$
\frac{h_{i}^{n}-h_{i}^{n-1}}{h_{i}^{n-1}} \leq 0.01
$$


2.7 Friction Calculations: Frictional power is a crucial factor for characterising their performance. Under modern high-speed conditions, it is important to also understand the frictional behaviour of the system. Roller bearings often operate within the mixed elastohydrodynamic regime of lubrication. Friction is generated by a combination of viscous shear of the lubricant and asperity interactions. Total friction at the mixed-EHL contact is a combination of the boundary friction, $f_{b}$, and hydrodynamic or viscous friction, $f_{v}$ :

$$
f=f_{v}+f_{b}
$$

Boundary friction is a function of asperity contact pressure, calculated using the Greenwood and Tripp model in this paper [29]:

$$
f_{b}=\tau_{0} A_{a}+\varsigma W_{a}
$$

where $\tau_{0}$ is the Eyring shear stress of lubricant and $\zeta$ is the pressure coefficient for shear strength of asperities, obtained from asperity level friction measurement. Asperity load, $W_{a}$, and area occupied by asperities within the apparent contact $A_{a}$ are obtained as below assuming a Guassian distribution of asperity peak counts:

$$
W_{a}=\frac{16 \sqrt{2}}{15} \pi(\zeta \kappa \sigma)^{2} \sqrt{\frac{\sigma}{\kappa}} E_{r} A_{a} F_{5 / 2}(\lambda)
$$

and

$$
A_{a}=\pi^{2}(\zeta \kappa \sigma)^{2} A F_{2}(\lambda)
$$

where $\lambda=\frac{h}{\sigma}$ is the Stribeck parameter and $F_{5 / 2}(\lambda)$ and $F_{2}(\lambda)$ are statistical functions obtained from numerical integration of the Guassian distribution of asperities.

Viscous Friction due to shearing of the lubricant film in the EHL contact is found using the below experimentally validated formulae [30]:

$$
f_{v}=\mu W
$$

where

$$
\mu=0.87 \alpha \tau_{0}+1.74 \frac{\tau_{0}}{\bar{p}} \ln \left[\frac{1.2}{\tau_{0} h}\left(\frac{2 K \eta_{0}}{1+9.6 \xi}\right)^{\frac{1}{2}}\right]
$$

where $\bar{p}$ is the average pressure at the apparent contact, $K$ is the lubricant thermal conductivity and $\xi$ is given by: 


$$
\xi=\frac{4}{\pi} \frac{K}{h / R_{z x}}\left(\frac{\bar{p}}{E_{r} R_{z x} K \rho^{\prime} c^{\prime} u}\right)^{\frac{1}{2}}
$$

where $K^{\prime}, \rho^{\prime}$, and $c^{\prime}$ are respectively the thermal conductivity, density, and specific heat capacity of the contacting solid.

To inform the boundary friction model, surface topography data are required. An Alicona InfiniteFocus Variation Microscope with a x10 objective was used for topography measurements to calculate the roughness parameter, $n \sigma \beta$. This had a vertical resolution of $30 \mathrm{~nm}$ and sampling point separation of $176.9 \mathrm{~nm}$ in the $y-z$ plane of the roller and $1 \mathrm{~nm}$ in $x$. An area of 530 by $588 \mu \mathrm{m}$ was captured. Data was processed using Vision65 Map Premium, where the profile of the radius of the roller was removed. The measured parameters are presented in Table 1.

Table 1 - Surface Topography Data

\begin{tabular}{cc}
\hline Root-mean-square height & $0.197 \mu \mathrm{m}$ \\
Density of peaks & $0.001161 /(\mu \mathrm{m})^{2}$ \\
Arithmetic mean peak curvature & $0.1801 / \mu \mathrm{m}$ \\
\hline
\end{tabular}

2.8: Explicit Numerical EHL Model: Whilst the analytical solution used in the implicit tribological model provides central film thickness, the film thickness and pressure distributions can only be obtained explicitly through the full solution of Reynolds equation in conjunction with rheological and elastic field models. In a line contact, where contact dimensions in the side-leakage direction $\left(y_{c}\right)$ are much larger than the direction of entraining motion $\left(x_{c}\right)$, pressure in $y_{c}$ direction is assumed constant due to the negligible gradient and the contact can be analysed in one dimension. This assumption is valid in the contact apart from small regions near the edge. Reynolds equation is used to calculate contact pressures. Assuming a thin film of Newtonian lubricant in a line contact, the following form is used in this paper:

$$
\frac{\partial}{\partial x_{c}}\left[\frac{\rho h^{3}}{\eta} \frac{\partial p}{\partial x_{c}}\right]-6 U \frac{\partial(\rho h)}{\partial x_{c}}=0
$$

where $x_{c}$ is the direction of entraining motion into the contact. For the pressure-density relationship in the compressible model, the Dowson-Higginson model [31] is used

$$
\rho=\rho_{0}\left(1+\frac{0.6 \times 10^{-9} p}{1+1.7 \times 10^{-9} p}\right)
$$


The increase in lubricant viscosity with pressure is modelled using Roelands equation [32] due to its known accuracy at higher contact EHL pressures;

$$
\eta=\eta_{0} \exp \left\{\left(\ln \left(\eta_{0}\right)+9.67\right) \times\left[-1+\left(1+5.1 \times 10^{-9} p\right)^{z_{0}}\right]\right\}
$$

where,

$$
z_{0}=\frac{\alpha}{5.1 \times 10^{-9}\left(\ln \left(\eta_{0}\right)+9.67\right)}
$$

It should be noted that equations 27 and 28 can reasonably model common lubricants for the application investigated in this work. For special lubricant with bespoke additive packages and non-conventional behaviour, alternative models can be utilised. The pressure distribution is obtained from the variations in film thickness at the contact, which is defined as below:

$$
h=h_{0}+\frac{x_{c}^{2}}{2 R_{z x}}-\frac{2}{\pi E_{r}} \int_{x_{c, \text { in }}}^{x_{c, \text { out }}} p \ln \left(x-x^{\prime}\right)^{2} d x^{\prime}
$$

where $h_{0}$ is the central film thickness, the second term represents an idealised film thickness parabola, with the ultimate term representing the localised contact deflection. Below, the method of solution for the numerical EHL model is provided:

Step 1. Input the load value obtained from the implicit tribological model for an instantaneous position as well as contact kinematics from experimental conditions.

Step 2. An initial estimation of lubricant film thickness, $h_{0}$ is made.

Step 3. Inlet and outlet distances set from $-4.5 a$ to $1.5 a$ based on the contact half width calculation. This sets up the computational domain.

Step 4. Pressure distribution and film thickness are obtained through simultaneous solutions of equations (2529). Newton-Raphson iterative scheme is used for speed and robustness of convergence [33]. Pressure convergence criterion is required for the iterative solution:

$$
\operatorname{Err}_{\text {pressure }}=\frac{\sum_{i=1}^{n}\left|p_{\text {new }}-p_{\text {old }}\right|}{\sum_{i=1}^{n} p_{\text {old }}} \leq \varepsilon_{p}
$$

where $\varepsilon_{p}=1 \times 10^{-5}$.

Under-relaxation is applied between successive iterations where the criterion is not met:

$$
p_{\text {new }}=(1-\gamma) p_{\text {old }}+\gamma p_{\text {new }}
$$


where the under-relaxation factor is typically $0.01 \leq \gamma \leq 0.8$.

Step 5. Hydrodynamic reaction load is calculated using the integration of pressure over the computational domain

$$
W_{h}=L \int p d x
$$

The total reaction from the hydrodynamic load should be equal to the total load share on the roller, $W_{i}$, obtained from the explicit tribological model. The following convergence criterion is applied:

$$
\frac{\left|W_{i}-W_{h}\right|}{W_{i}} \leq \varepsilon_{W}
$$

where $\varepsilon_{w}=0.001$. 


\section{Validation and Verification of Results}

3.1 Experimental Result Verification: The experimental results obtained from the presented rig were verified against analytically calculated frequency contents. This was to ensure the correct post processing of data for the input to numerical models. The bearing and lubricant data properties are given in Tables 2 and 3 respectively which were also used in simulations.

Table 2 - Bearing Specification

\begin{tabular}{cc}
\hline Inner Race Bore & $25 \mathrm{~mm}$ \\
Inner Race Diameter & $31.5 \mathrm{~mm}$ \\
Outer Race Diameter & $46.5 \mathrm{~mm}$ \\
Roller Diameter & $7.5 \mathrm{~mm}$ \\
Roller Length & $9 \mathrm{~mm}$ \\
Number of Rollers & 12 \\
External Load & $740 \mathrm{~N}$ \\
Radial Interference & $0 \mu \mathrm{m}$ \\
\hline
\end{tabular}

Table 3 - Lubricant and Material Properties

\begin{tabular}{cc} 
Pressure Viscosity Coefficient $(\alpha)$ & $2.1 \times 10^{-8} \mathrm{~Pa}^{-1}$ \\
Atmospheric lubricant dynamic viscosity $\left(\eta_{0}\right)$ & $0.08 \mathrm{~Pa} . \mathrm{s}$ \\
Lubricant inlet density $\left(\rho_{0}\right)$ & $833.8 \mathrm{~kg} \cdot \mathrm{m}^{-3}$ \\
Eyring stress $\left(\tau_{0}\right)$ & $2 \mathrm{MPa}$ \\
Shear strength of asperities $(\varsigma)$ & 0.3 \\
Thermal conductivity of fluid & $1600 \mathrm{~W} \cdot \mathrm{m}^{-1} \cdot \mathrm{K}^{-1}$ \\
Modulus of elasticity of contacting solids & $210 \mathrm{GPa}$ \\
Poisson's ratio of contacting solids & 0.3 \\
Density of contacting solids & $7850 \mathrm{~kg} \cdot \mathrm{m}^{-3}$ \\
Thermal conductivity of contacting solids & $46 \mathrm{~W} \cdot \mathrm{m}^{-1} \cdot \mathrm{K}^{-1}$ \\
Specific heat capacity of contacting solids & $470 \mathrm{~J} \cdot \mathrm{kg}^{-1} \cdot \mathrm{K}^{-1}$ \\
\hline
\end{tabular}


Primary frequencies in the system due to the interaction of the rolling elements, races and the shaft could then be verified. These frequencies were calculated analytically, with $\boldsymbol{f}_{\boldsymbol{b p} \boldsymbol{i}}$ and $\boldsymbol{f}_{\boldsymbol{b p o}}$ representing the ball pass frequencies of the inner and outer race respectively and $\boldsymbol{f}_{\text {shaft }}$ being the rotational frequency of the shaft:

$$
\begin{gathered}
f_{b p i}=\frac{\omega_{s}}{2 \pi} \frac{N}{2}\left(1-\frac{D_{r}}{D_{p}}\right) \\
f_{\text {bpo }}=\frac{\omega_{s}}{2 \pi} \frac{N}{2}\left(1+\frac{D_{r}}{D_{p}}\right) \\
f_{\text {shaft }}=\frac{\omega_{s}}{2 \pi}
\end{gathered}
$$

At $14000 \mathrm{rpm}$, the theoretical inner and outer race frequencies are calculated to be $1669 \mathrm{~Hz}$ and $1131 \mathrm{~Hz}$ respectively, with the experimental results being $1611 \mathrm{~Hz}$ and $1131 \mathrm{~Hz}$. The first order shaft rotational frequency from the experiment was $232 \mathrm{~Hz}$ compared to theoretical calculation of $233 \mathrm{~Hz}$. The above frequencies can be seen clearly in Figure 7, which shows the bearing bore displacement spectra, and Figure 8 which represents the shaft displacement spectra. The verification frequencies are identical in both, confirming that the bearing motion is accurately measured by the experimental methodology. It is observed that at certain speeds, ball pass frequency of outer race has larger contribution than the inner race. This is particularly highlighted at 12000-14000 rpm. These regional effects are contributed by modal behaviour of the bracket and the bed. The critical speed of the unloaded shaft, where lateral bending frequency of the shaft is equal to the rotation frequency [34], occurs at $12660 \mathrm{rpm}$ and $211 \mathrm{~Hz}$. 


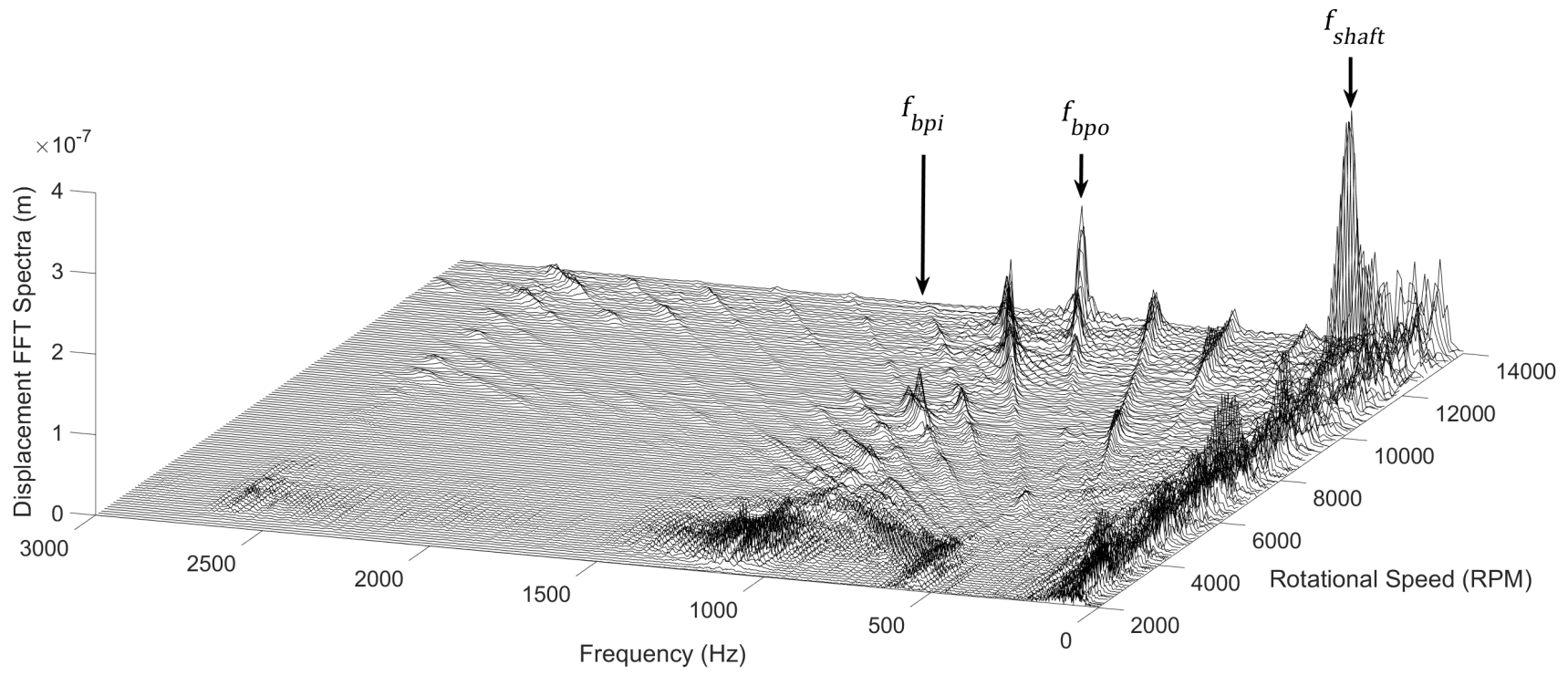

Figure 7 - Bearing Bore Displacement Frequency Spectra

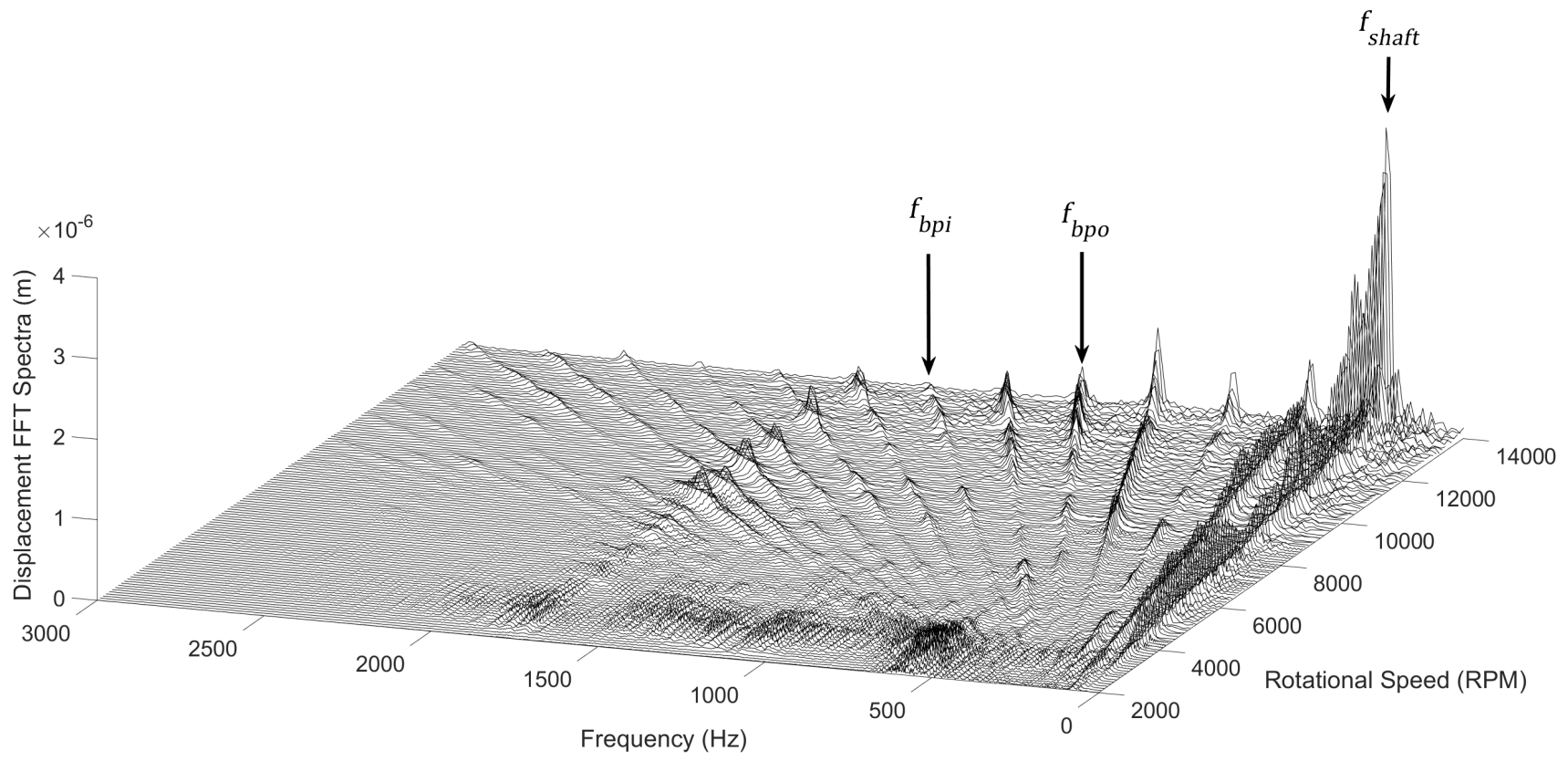

Figure 8 - Shaft Displacement Frequency Spectra

3.2 Numerical EHL Validation: Conjunction level validation of the numerical method for solving the EHL film thickness and pressure distributions was performed using the work of Masjedi and Khonsari [35]. These were validated against their smooth surface plots with no asperity pressure contribution. The dimensionless input parameters were $W^{*}=1 \times 10^{-4}, U^{*}=1 \times 10^{-11}$ and $G^{*}=4500$. The results shown in Figure 9 and Figure 10 show a good agreement between the model used in the study and the work of Masjedi and Khonsari for the dimensionless pressure, $P$, and dimensionless film thickness, $H$. 


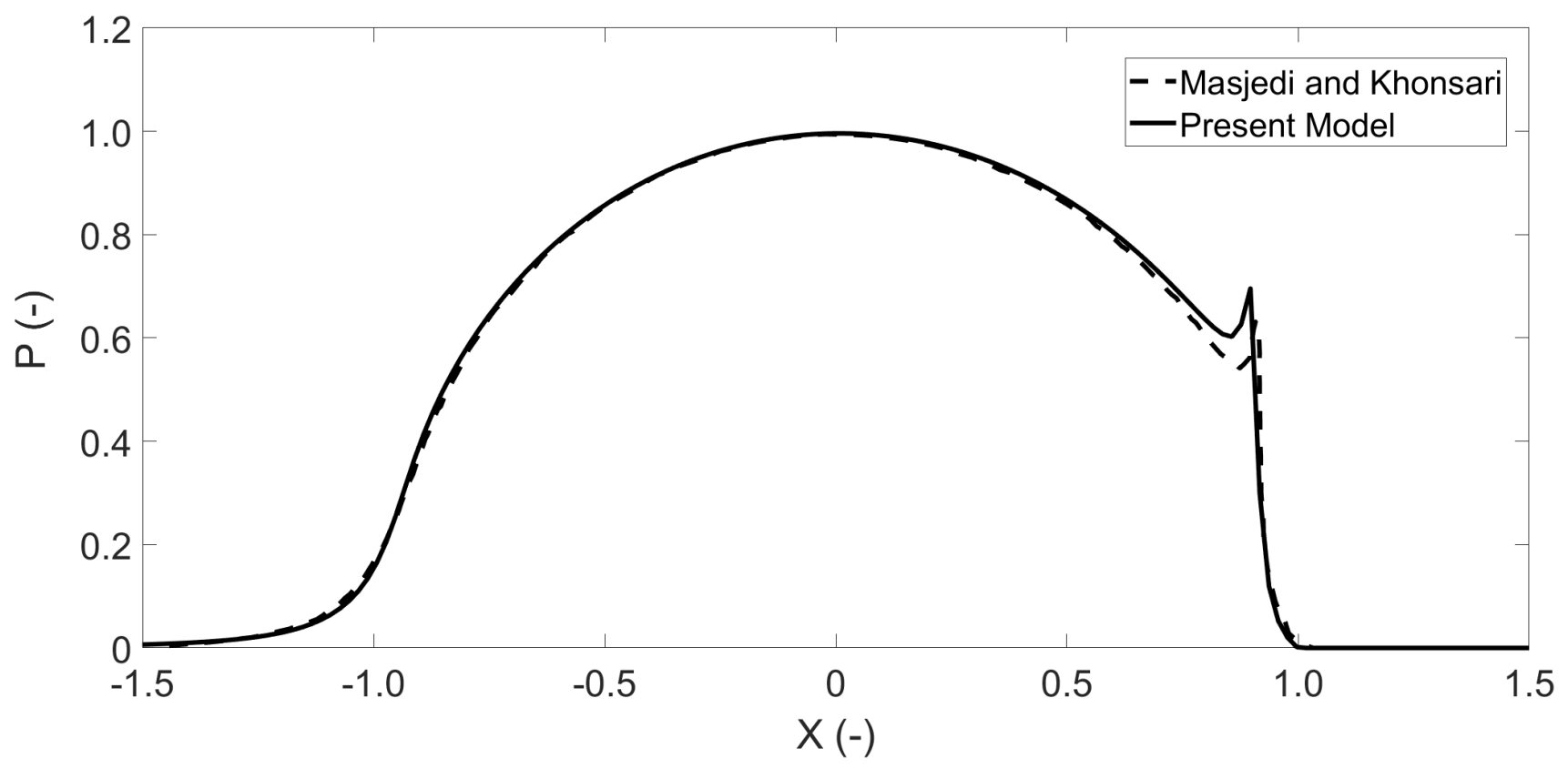

Figure 9 - Validation of dimensionless pressure distribution, present model (solid), Masjedi and Khonsari (dashed)

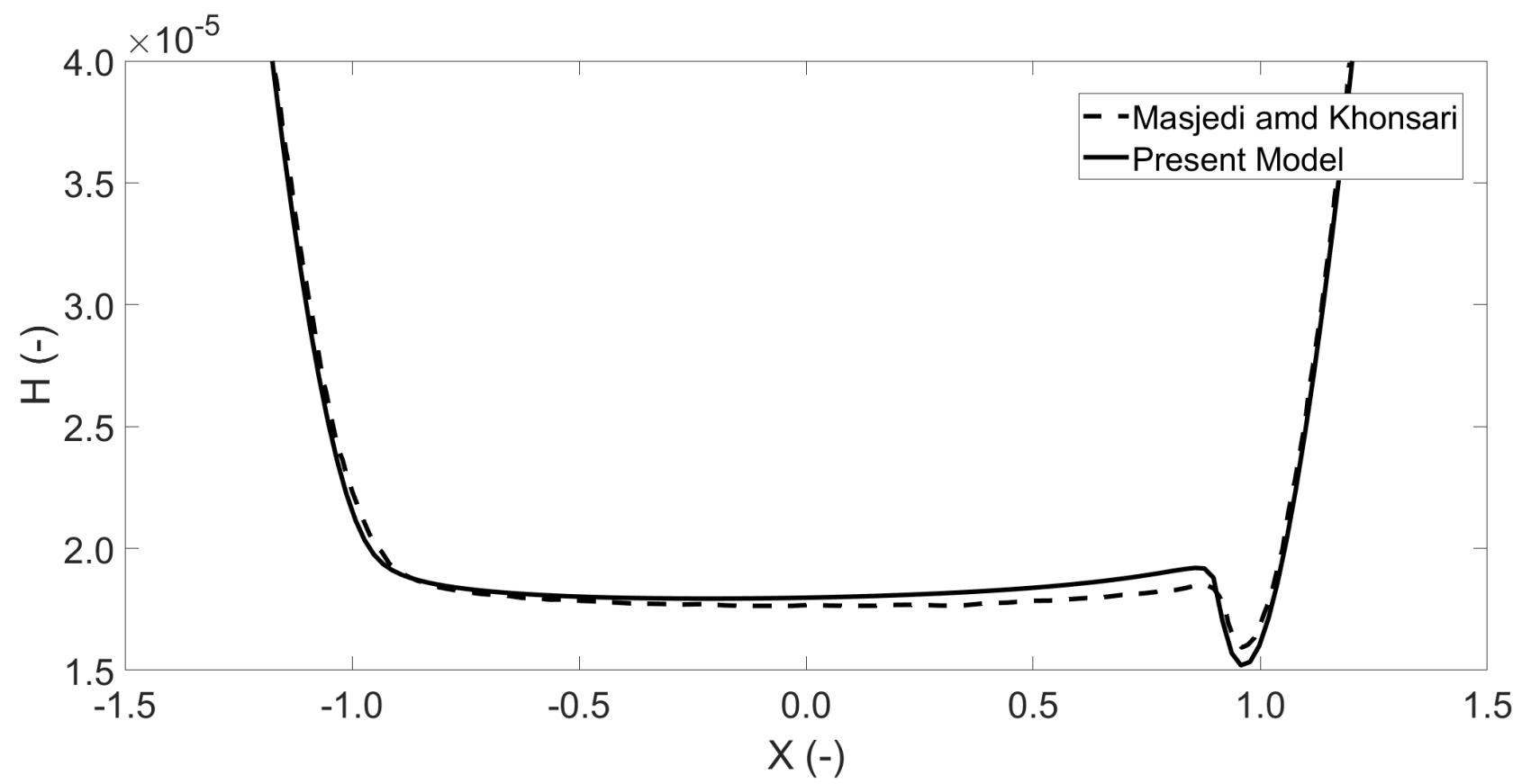

Figure 10 - Validation of dimensionless film thickness distribution, present model (solid), Masjedi and Khonsari (dashed) 


\section{Results and Discussion}

This section presents the results of the numerical tribological models. The dynamic measurements presented in Section 3 are used as the boundary conditions to the implicit and explicit models.

\subsection{Film thickness and load across speed sweep}

The variation in EHL film thickness and roller contact load across the speed sweep from 0 - $15000 \mathrm{rpm}$ at the outer race contact are shown in Figure 11. Only the EHL regions are shown, where loads are significant enough to cause contact deformation. The upper limit of the film is where the roller and races diverge and approach the hydrodynamic regime where the film is hence governed by the entraining motion of lubricant into the contact. The lubricant film, as seen from the film thickness equation, is more affected by the speed of entraining motion rather than the load. This explains the increasing film thickness values in Figure 11 despite increasing load. The film thickness is increased from 0.1 to $1.9 \mu \mathrm{m}$ across the speed sweep, revealing a significant increase that can affect the tribo-dynamic behaviour of the bearing, as explained in following sections. From the tribological model, it is possible to observe the transition between mixed-EHL to the purely hydrodynamic regime as the roller passes in and out of the loaded region of the bearing. Full system and rotor dynamics also contribute to the total load on the roller, with periods of resonance at $3000 \mathrm{rpm}$ and 14000 rpm marked as A and B respectively in Figure 11.

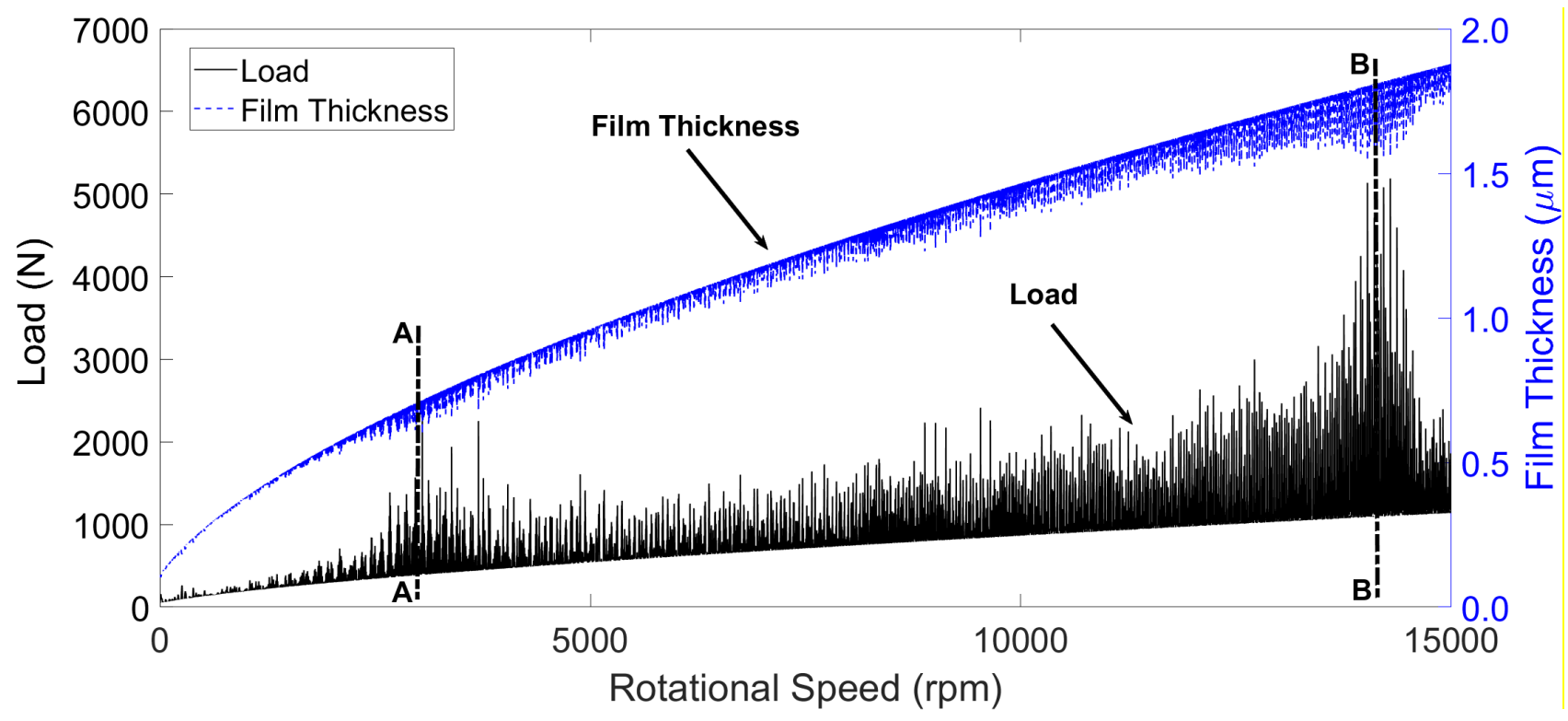

Figure 11 - Contact Load and Film Thickness - Outer Race

Figure 12 presents an interval of the speed sweep where the effect of the EHL load on reducing the film thickness under oscillating conditions can be observed and the hydrodynamic film growth as the roller is unloaded. It is possible to see the effect of the resonant frequency at $1765 \mathrm{~Hz}$ superimposed on the lower fundamental train frequency within the loaded region as the inner and outer rings converge and diverge. The 
results in Figure 12 confirm the significant effect of dynamic behaviour as well as multi-regime nature of the lubrication due to dynamic effects.

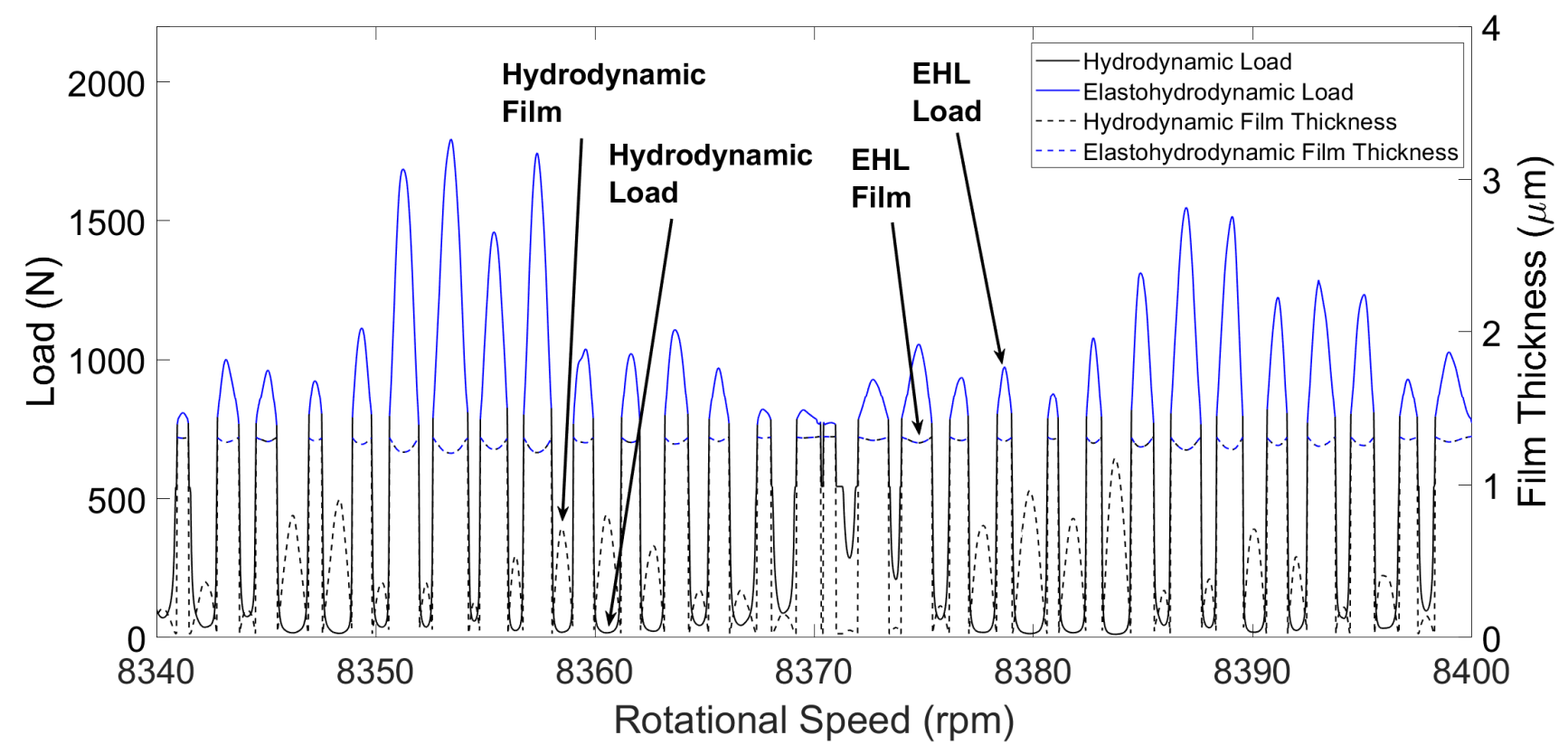

Figure 12 - Film and Load - EHL to Hydrodynamic Regime

\subsection{Friction}

Focussing on data from the EHL regime, boundary and viscous friction through the speed sweep can be analysed. Figure 13 shows the boundary and viscous frictions across the speed sweep. As the film thickness increases with speed, the separation of the contacting surfaces increases, reducing the boundary interaction of asperities. The resonant period at $14000 \mathrm{rpm}$ reduces the film height, increasing the likelihood of asperity interaction in that region and hence boundary friction and potential for wear. In general, the boundary friction reduces towards higher rotational and entrainment velocities. This does not, however, account for lubricant inlet starvation at high speeds or roller sliding. Viscous friction increases with higher speed and hence the shear as expected. Although the film thickness also increases at higher speeds which may reduce the amount of shear, the effect of increasing speed is more dominant. The peak values occurring again at a resonance speed of $14000 \mathrm{rpm}$ where the highest loads and smallest film occurs. 


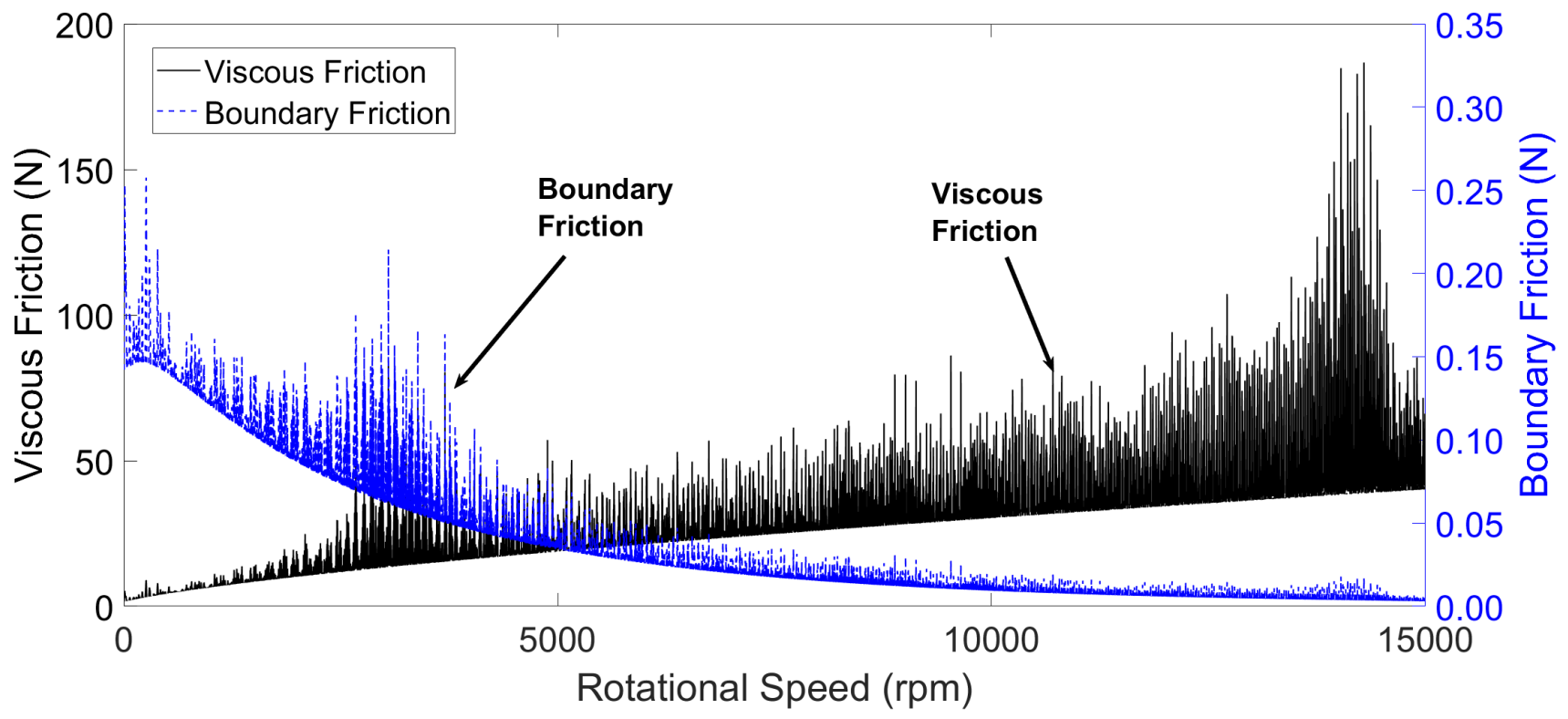

Figure 13 - Viscous and Boundary Friction at Outer Race Contact

\subsection{EHL Regimes}

As has been demonstrated in the results analysis, the contact conditions deviate from the elastohydrodynamic regime of lubrication into the hydrodynamic regime throughout the roller orbital motion. These conditions can be verified by presenting the results on the Greenwood chart for fluid regimes of lubrication. The charts display the physical effects instrumental to EHL formation under isothermal conditions: viscosity rise due to pressure and elastic deformation of the surface. These two effects are quantified by two dimensionless parameters, $G_{e}$ and $G_{v}$, as defined below [17]:

$$
\begin{gathered}
G_{e}=\frac{W^{*}}{U^{* 1 / 2}} \\
G_{v}=\frac{W^{* 3 / 2} G^{*}}{U^{* 1 / 2}}
\end{gathered}
$$

Four regions exist and the boundaries of these regions are defined by the geometry of contacting bodies, material, and lubricant properties. As is shown in Figure 14, the outer roller-race contact conditions move between the viscous elastic and iso-viscous rigid regimes, representing EHL and hydrodynamic respectively. The viscous elastic regime signifies the EHL regime of lubrication where contact pressures are such that elastic deformation of the surfaces and viscosity rise due to pressure increase is significant. The iso-viscous rigid regime occurs when the magnitude of elastic deformation is insignificant, and the contact pressures are low enough that viscosity rise is negligible, i.e. hydrodynamic lubrication [36]. The boundary between the two also 
corresponds well with the distinction being made between hydrodynamic and EHL in this methodology, presented by the black and blue regions of the plot.

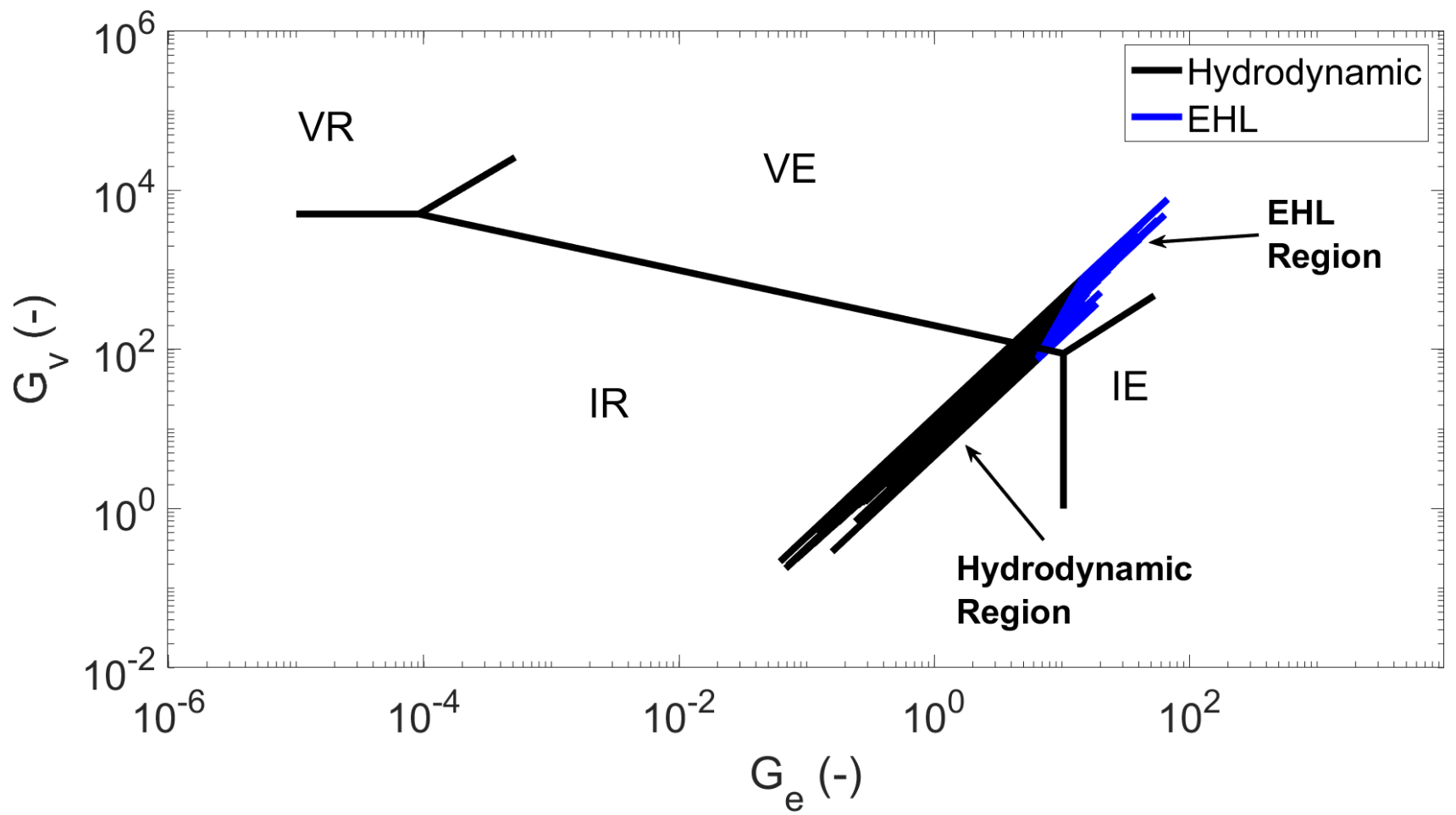

Figure $14-E H L$ and hydrodynamic conditions during roller operation. Key: $I R=I$ so-viscous Rigid, $V R=$ Viscous Rigid, VE $=$ Viscous Elastic, IE = Iso-viscous Elastic

\subsection{Dry vs Lubricated Tribo-Dynamic Model}

Previously presented results confirmed the significance of considering tribo-dynamic coupling on the tribological predictions. The aim of this section is to assess the significance of this coupling on dynamics via affecting contact load and stiffness values. The surface deformation at the EHL contact is further exacerbated by the presence of the lubricant film. Since the contact load and contact stiffness are governed by this deformation, neglecting the film leads to an underestimation of the total load at the roller-race contact. At higher speeds, such as those present in modern electrified powertrains, the growth of the lubricant film due to the increased entraining motion into the conjunction cannot be neglected - as is shown in Figure 11 with a film growth from 0.1 to $1.9 \mu \mathrm{m}$. The implicit tribological model was run for two cases, including and negating lubricant film thickness in the deformation obtained from equation 5 . The difference in magnitude at each time step is computed, and the increase in load magnitude between a dry and lubricated model is calculated. For EHL loads, the magnitude of the load difference through the speed sweep is plotted in Figure 15. 


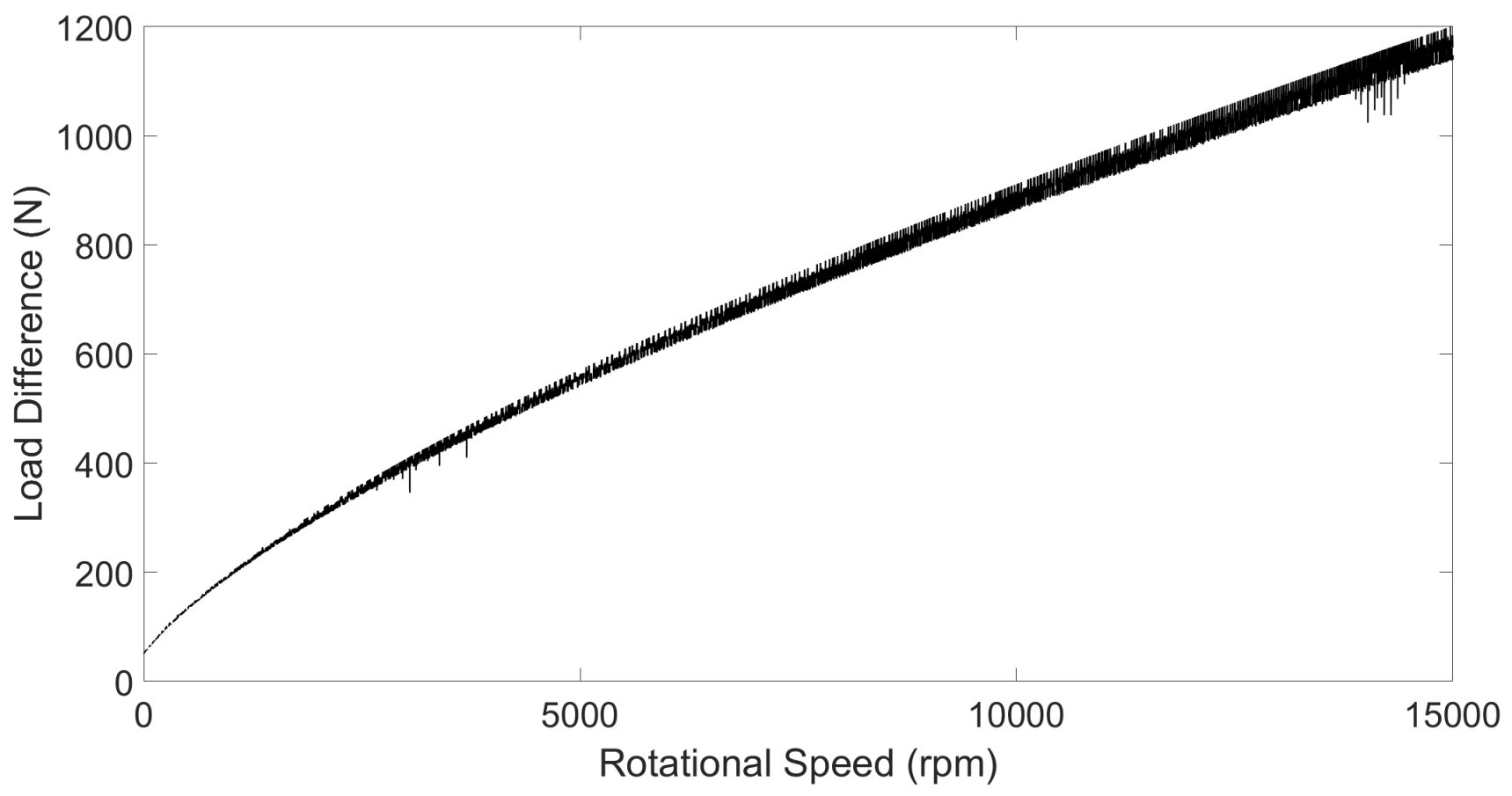

Figure 15 - Contact Load Difference Between Dry and Lubricated Model

There is an increasing load difference across the speed sweep, with fluctuations arising from the dynamics of the system. It is clear that neglecting lubricant film thickness leads to significant underestimation of the contact load, hence inaccurate dynamics as well as tribological calculations. This effect gains more significance at higher speeds which highlights the necessity of considering tribo-dynamic coupling for high-speed conditions in electrified powertrains. To fully understand the requirement for a lubricated bearing model, the percentage difference between both cases is presented at three different rotational speed snapshots of $3050 \mathrm{rpm}, 14135 \mathrm{rpm}$, and $14855 \mathrm{rpm}$ in Figure 16. At low speeds and relatively low dynamic load, the addition of the film contributes to a $14.8 \%$ greater load prediction than a dry model, showing that the film inclusion has a significant contribution even at low rotational speeds. At shaft speeds of $14135 \mathrm{rpm}$, the first order resonance in the system, as shown in the frequency plots, creates high dynamic loading. At peak load, the growth of the film is still present, however, the high contact deformation is close to the magnitude of the film growth, hence the difference between dry and lubricated model reaches $25.1 \%$. As the system passes through this resonant region and the overall dynamic load is reduced, the percentage load difference reaches values as high as $149 \%$ as the effect of the film growth at high speeds exceeds that of the surface deformation. 

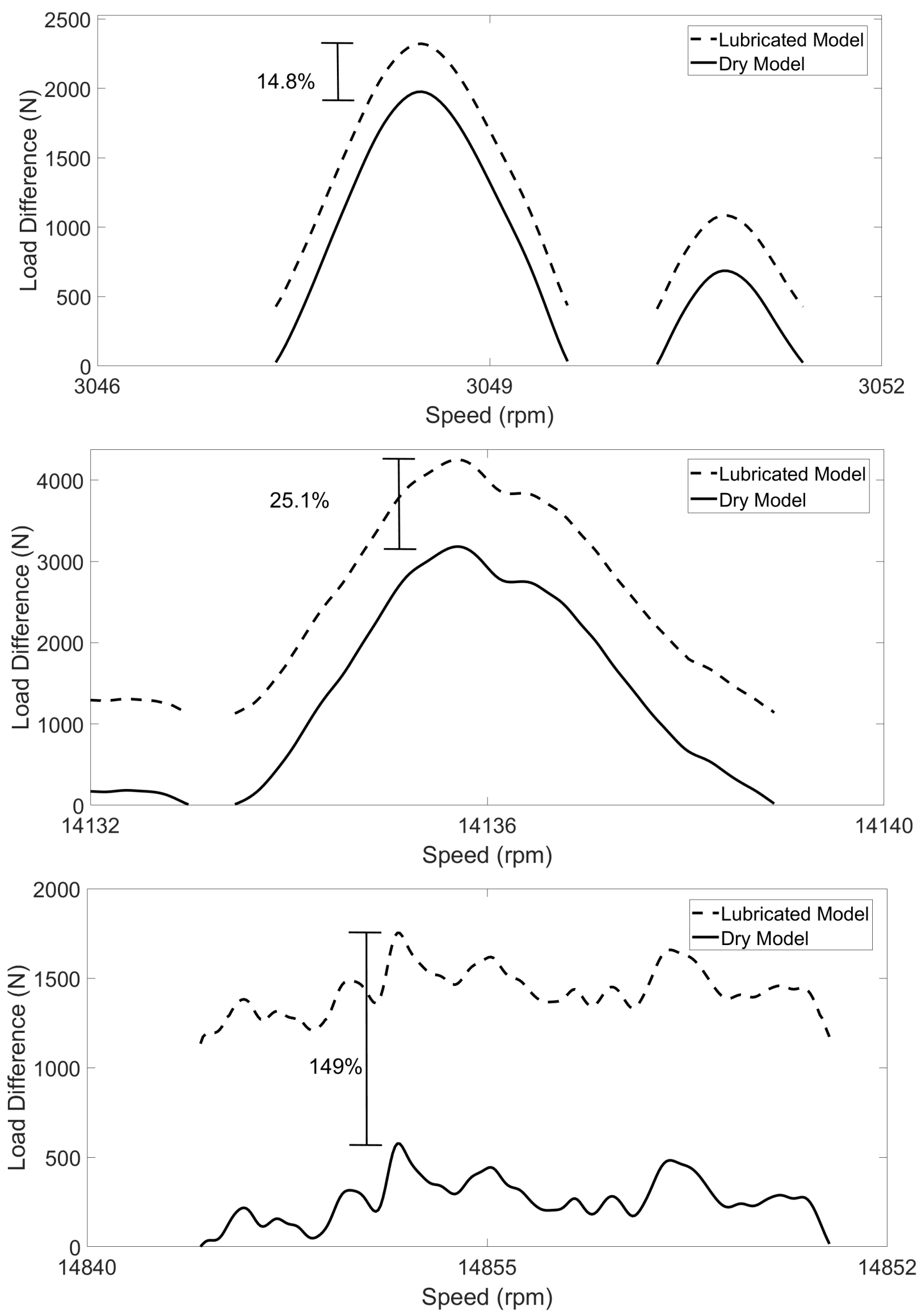

Figure 16 - Dry and lubricated model load difference: a) 3050 rpm, b) 14135 rpm, c) 14855 rpm 
At high speeds in periods of resonance, the magnitude of the bearing load dominates, and the effect of the increasing film thickness with speed diminishes in regions of resonance. The percentage difference between the dry and lubricated model is lower as the external force and corresponding surface deformation prevails the effect of the film. However, at high speeds outside of this period of resonance, the film thickness is of the same order as the deformation and the percentage difference between the two models is much greater.

\subsection{Numerical EHL Results}

Full numerical simulation is required to obtain detailed pressure and film thickness distributions. These distributions reveal the realistic pressure and film values at the contact for in depth durability, efficiency and thermal analysis. At $8350 \mathrm{rpm}$, focussing on one roller orbit, the selected points for EHL numerical analysis are shown in Figure 17. These load values are found from the implicit tribological model when the roller enters the loaded region of the bearing. The corresponding points on the bearing circumference are also shown.

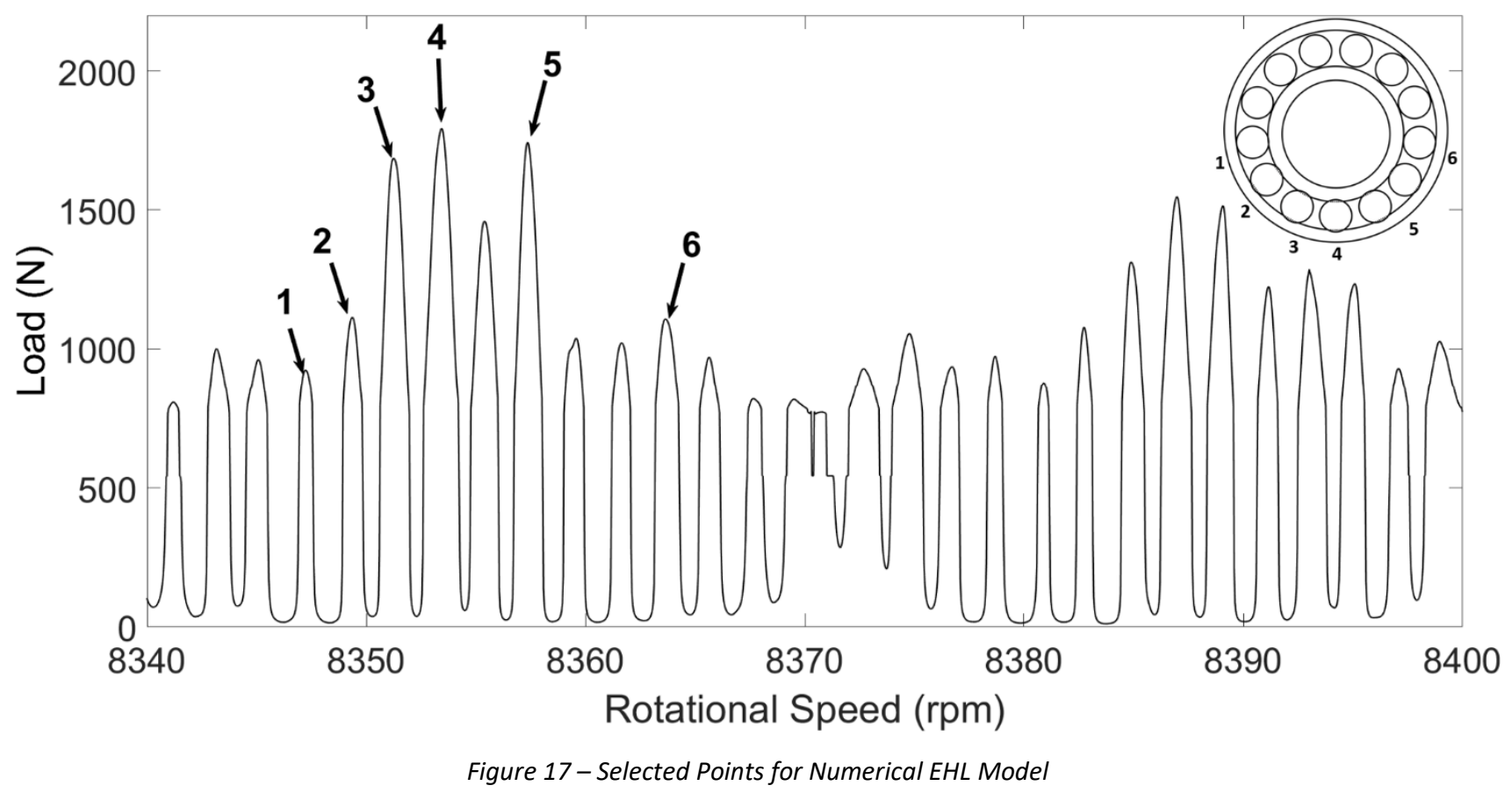

The load values are passed explicitly to the numerical EHL model along with entrainment velocity, lubricant and solid properties. From the nodes presented, the pressure distribution and film thickness across the contact are obtained. These are presented in Figure 18. 

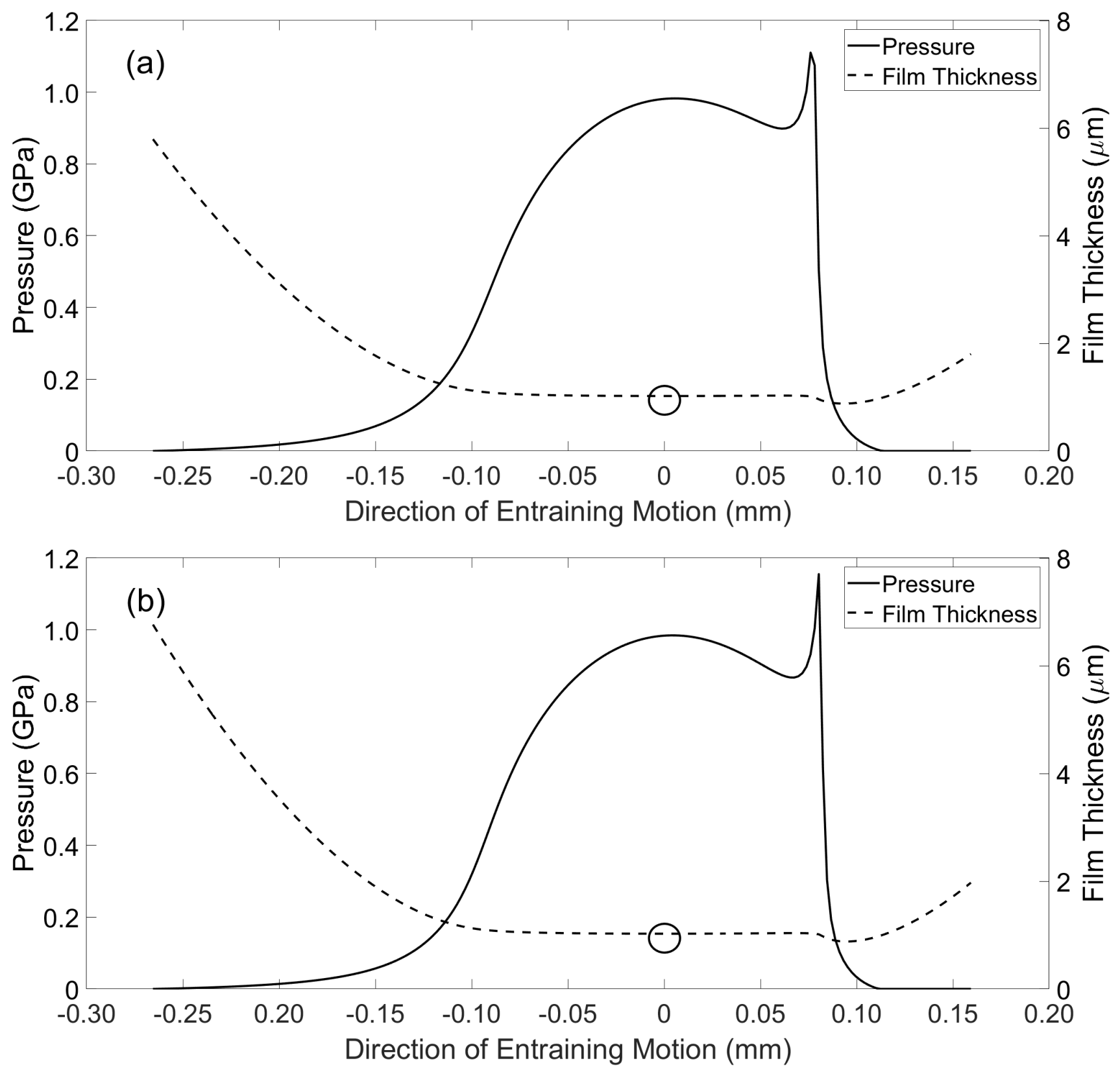

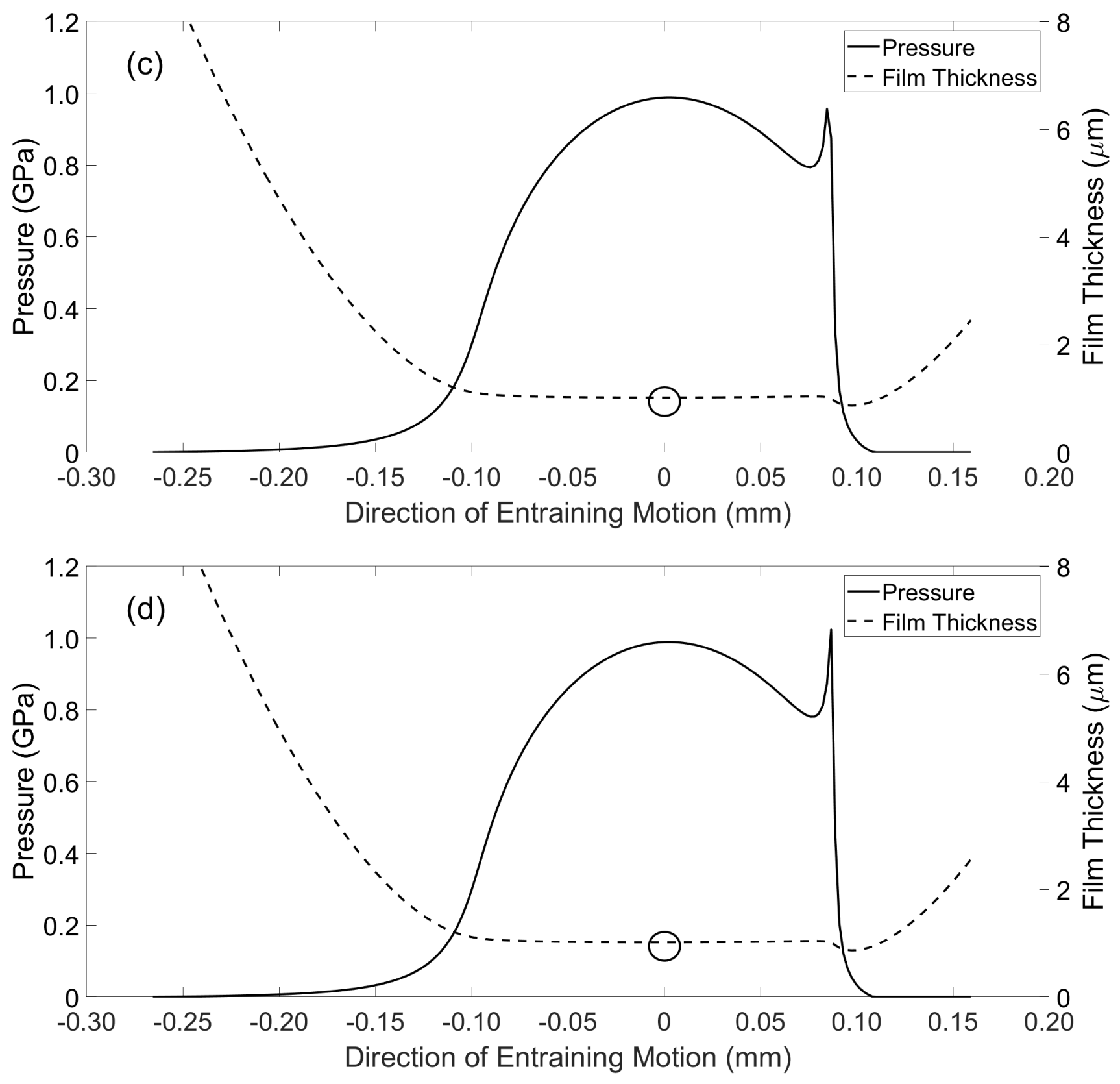

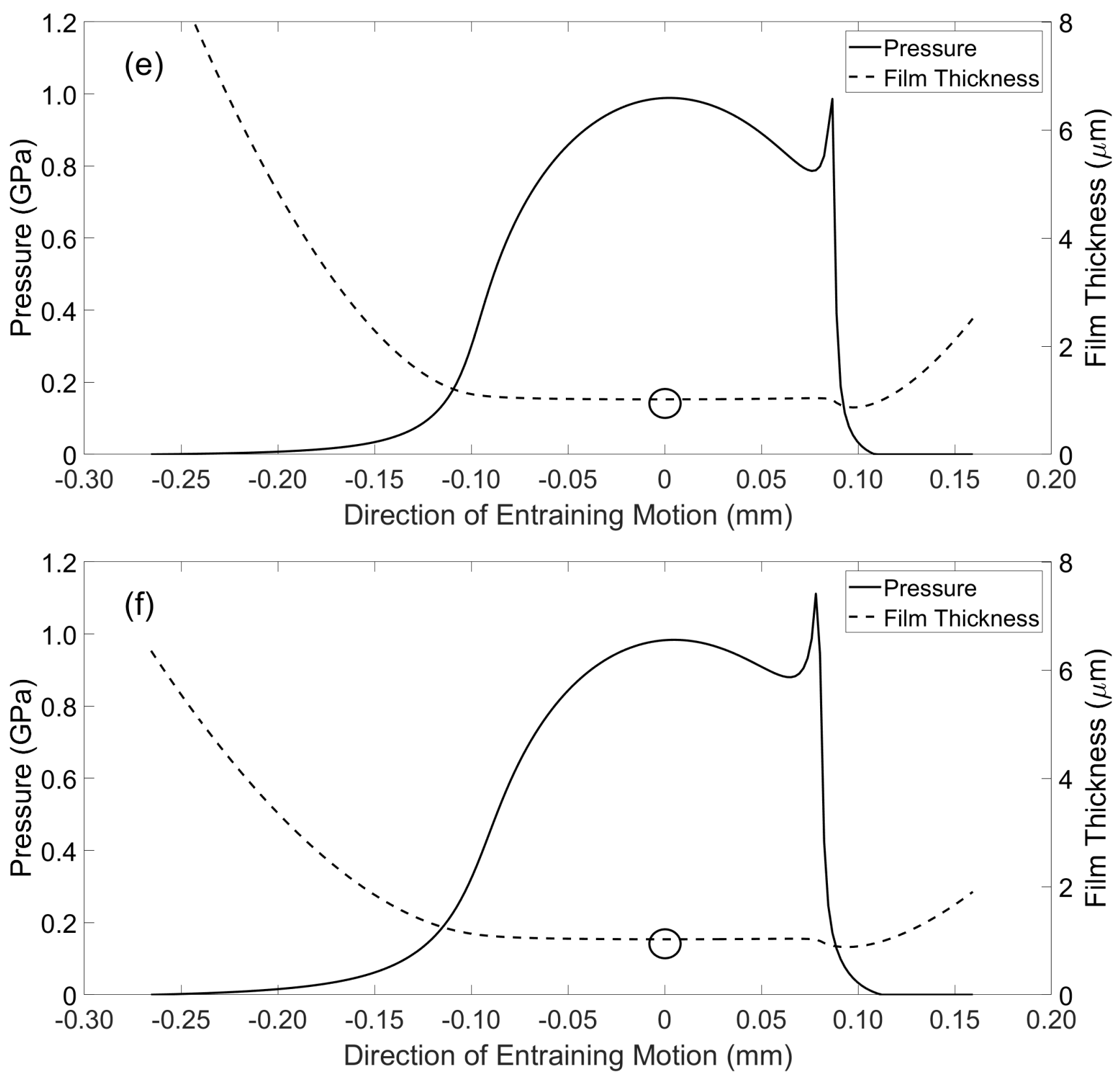

Figure 18 - EHL Pressure and Film Thickness Distributions: a) Node 1, b) Node 2, c) Node 3, d) Node 4, e) Node 5, f) Node 6

In each of these plots, it is possible again to see the central film thickness drop as the roller enters, then exits the loaded region. These central film values are represented by circles in Figure 18. Agreement between the extrapolated film formulae and the numerical model for calculating central film values are presented in Table 4. This confirms the validity of using extrapolated film thickness equation in the implicit tribological model. It is shown that the central nodes which correspond to the higher loads in the loaded region have the lowest percentage difference in comparison to the lightly loaded nodes at the outer edges. 
Table 4-Extrapolated film formulae and numerical model central film thickness comparison

\begin{tabular}{cccc}
\hline Node & $\begin{array}{c}\text { Extrapolated Formulae } \\
\text { Central Film Thickness }(\mu \mathrm{m})\end{array}$ & $\begin{array}{c}\text { Numerical Model Central Film } \\
\text { Thickness }(\mu \mathrm{m})\end{array}$ & $\begin{array}{c}\text { Percentage } \\
\text { Difference }(\%)\end{array}$ \\
\hline 1 & 1.142 & 1.026 & 11.3 \\
2 & 1.122 & 1.025 & 9.46 \\
3 & 1.075 & 1.019 & 5.49 \\
4 & 1.068 & 1.016 & 5.11 \\
5 & 1.072 & 1.018 & 5.30 \\
6 & 1.122 & 1.025 & 9.46 \\
\hline
\end{tabular}

\section{Conclusions}

A new methodology comprising experiments and numerical modelling has been developed to allow component and conjunction level tribo-dynamic analysis of a roller bearing under speeds and loading conditions previously not reported. The experimental data contain the physics of the dynamics and tribology within the bearing, negating the need for a simplified and computationally intensive dynamic bearing model. The tribological conditions at the contact between an individual roller and raceways are numerically analysed. All possible lubrication regimes, including mixed-EHL and hydrodynamic, are considered as the roller passes through loaded and unloaded regions.

The presented research investigates a new range of working conditions under high speeds, representative of modern electrified powertrains. This study helps to understand the prevailing regimes of lubrication as well as range of tribological quantities. Additionally, the interaction of tribological behaviour with dynamics of the system is investigated. The deeper and comprehensive understanding of these matters will support objective development of electrified powertrains in the future towards higher efficiency, durability and NVH refinement. The acquired knowledge and understanding will also support future developments of predictive tools by understanding the interaction of tribology and dynamics and the significance of considering this multi-physics interaction. The following conclusions can be made based on presented results:

- The contact experiences an order of magnitude increase in film thickness across the speed sweep. This highlights the necessity of implicitly including the lubricant film in any predictive tribo-dynamic model; an approach that is not reported on in open literature for high-speed dynamic roller bearing analysis.

- A comparison between the dry and lubricated contact model further reinforces the need to include the lubricant film in high-speed roller bearing analysis, with percentage differences in load between both models up to $149 \%$ at $15000 \mathrm{rpm}$. Neglecting this film by using the common dry Hertzian approach would lead to an underestimation of the total load at the roller-race contact. 
- At higher speeds, such as those present in modern electric powertrains, it is shown that the growth of the lubricant film must be included implicitly within the dynamic bearing analysis.

- The load values obtained from the lubricated tribological model have been used explicitly within a 1dimensional EHL model to calculate the pressure distribution and film thickness across the contact. The workflow of using an explicit EHL model based on the analytical tribological contact mechanics is valid, with good agreement between central film thickness values for both.

- The explicit EHL approach significantly improves the computational efficiency of the model whilst maintaining accuracy, since only the central value of the film is required in the load calculation. This can be implicitly coupled to broaden the scope of the analysis that is being performed.

\section{Acknowledgement}

The authors wish to acknowledge the support of the Loughborough University Wolfson School of Mechanical, Electrical and Manufacturing Engineering PhD Studentship Scheme and the support of AVL List GmbH.

\section{References}

[1] X. Mosquet, H. Zablit, A. Dinger, G. Xu, M. Andersen, and K. Tominaga, 'The Electric Car Tipping Point', 2018.

[2] L. I. Farfan-Cabrera, 'Tribology of electric vehicles: A review of critical components, current state and future improvement trends', Tribol. Int., vol. 138, no. June, pp. 473-486, 2019.

[3] J. A. Wensing, 'The dynamics of ball bearings', Wear, vol. 19, no. 3, p. 360, Mar. 1972.

[4] X. Hao, J. Zhai, J. Liang, Y. Chen, and Q. Han, 'Time-varying stiffness characteristics of roller bearing influenced by thermal behavior due to surface frictions and different lubricant oil temperatures', Tribol. Int., vol. 144, no. December 2019, p. 106125, 2020.

[5] N. Akemi, H. Tsuha, and K. L. Cavalca, 'Finite line contact stiffness under elastohydrodynamic lubrication considering linear and nonlinear force models', Tribol. Int., p. 106219, 2020.

[6] R. Aini, H. Rahnejat, and R. Gohar, 'A five degrees of freedom analysis of vibrations in precision spindles', Int. J. Mach. Tools Manuf., vol. 30, no. 1, pp. 1-18, 1990.

[7] H. Rahnejat and R. Gohar, 'The Vibrations of Radial ball bearings', Proc. Inst. Mech. Eng. Part C J. Mech. Eng. Sci., vol. 199, no. 3, pp. 181-193, 1985.

[8] M. Mohammadpour, P. Johns-Rahnejat, and H. Rahnejat, 'Roller bearing dynamics under transient thermal-mixed non-Newtonian elastohydrodynamic regime of lubrication', Proc. Inst. Mech. Eng. Part KJ. Multi-body Dyn., vol. 229, no. 4, pp. 407-423, Dec. 2015. 
[9] M. D. Rajab, 'Modeling of the transmissibility through rolling-element bearings under radial and moment loads', 1982.

[10] T. C. Lim and R. Singh, 'Vibration transmission through rolling element bearings. Part II: Geared rotor system studies', J. Sound Vib., vol. 151, no. 1, pp. 31-54, 1991.

[11] R. D. Flack, G. J. Kostrzewsky, and D. V. Taylor, 'A Hydrodynamic Journal Bearing Test Rig with Dynamic Measurement Capabilities', Tribol. Trans., vol. 36, no. 4, pp. 497-512, Jan. 1993.

[12] L. D. Meyer, F. F. Ahlgren, and B. Weichbrodt, 'An Analytic Model for Ball Bearing Vibrations to Predict Vibration Response to Distributed Defects', J. Mech. Des., vol. 102, no. 2, pp. 205-210, Apr. 1980.

[13] M. Matsubara, H. Rahnejat, and R. Gohar, 'Computational modelling of precision spindles supported by ball bearings', Int. J. Mach. Tools Manuf., vol. 28, no. 4, pp. 429-442, 1988.

[14] F. Wang, M. Jing, J. Yi, G. Dong, H. Liu, and B. Ji, 'Dynamic modelling for vibration analysis of a cylindrical roller bearing due to localized defects on raceways', Proc. Inst. Mech. Eng. Part K J. Multi-body Dyn., vol. 229, no. 1, pp. 39-64, 2015.

[15] J. Liu, Z. Shi, and Y. Shao, 'An analytical model to predict vibrations of a cylindrical roller bearing with a localized surface defect', Nonlinear Dyn., vol. 89, no. 3, pp. 2085-2102, 2017.

[16] Y. Guo and J. Keller, 'Validation of combined analytical methods to predict slip in cylindrical roller bearings', Tribol. Int., vol. 148, no. April, p. 106347, 2020.

[17] R. Gohar, Elastohydrodynamics. London: Imperial College Press, 1988.

[18] A. N. Grubin, Fundamentals of the Hydrodynamic Theory of Lubrication of Heavily Loaded Cylindrical Surfaces, Book No. 3. Moscow (DSIR Translation): Central Scientific Research Institute for Technology and Mechanical Engineering, 1949.

[19] M. Denni, N. Biboulet, V. Abousleiman, and A. A. Lubrecht, 'Dynamic study of a roller bearing in a planetary application considering the hydrodynamic lubrication of the roller/cage contact', Tribol. Int., vol. 149, no. March 2019, p. 105696, 2019.

[20] P. K. Gupta, 'Dynamics of Rolling-Element Bearings-Part I: Cylindrical Roller Bearing Analysis', J. Lubr. Technol., vol. 101, no. 3, pp. 293-302, Jul. 1979.

[21] D. W. Dareing and K. L. Johnson, 'Fluid Film Damping of Rolling Contact Vibrations', J. Mech. Eng. Sci., vol. 17, no. 4, pp. 214-218, Aug. 1975.

[22] H. Mehdigoli, H. Rahnejat, and R. Gohar, 'Vibration response of wavy surfaced disc in elastohydrodynamic rolling contact', Wear, vol. 139, no. 1, pp. 1-15, 1990.

[23] J. Walker, H. Questa, S. R. Bewsher, C. Schweiger, and M. Sopouch, 'Experimental Design for Characterization of Force Transmissibility through Bearings in Electric Machines and Transmissions', in 10th International Styrian Noise, Vibration \& Harshness Congress: The European Automotive Noise Conference, 2018, pp. 1-6. 
[24] R. Takeda, G. Lisco, T. Fujisawa, L. Gastaldi, H. Tohyama, and S. Tadano, 'Drift Removal for Improving the Accuracy of Gait Parameters Using Wearable Sensor Systems', Sensors, vol. 14, no. 12, pp. 2323023247, Dec. 2014.

[25] T. A. Harris, Roller Bearing Analysis, 3rd ed. New York: John Wiley and Sons, 1984.

[26] B. J. Hamrock and D. Dowson, Ball Bearing Lubrication: The Elastohydrodynamics of Elliptical Contacts. New York: John Wiley * Sons, 1981.

[27] H. Rahnejat, 'Influence of vibration on the oil film in concentrated contacts', University of London, 1984.

[28] D. Dowson and S. Toyoda, 'A Central Film Thickness Formula for Elastohydrodynamic Line', Proc. Fifth Leeds-Lyon Symp. Tribol. Mech. Eng. Publ., pp. 60-65, 1979.

[29] J. A. Greenwood and J. H. Tripp, 'The Contact of Two Nominally Flat Rough Surfaces', Proc. Inst. Mech. Eng., vol. 185, no. 1, pp. 625-633, 1970.

[30] C. R. Evans and K. L. Johnson, 'Regimes of traction in elastohydrodynamic lubrication', Proc. Inst. Mech. Eng. Part C J. Mech. Eng. Sci., vol. 200, no. 5, pp. 313-324, 1986.

[31] D. Dowson and G. R. Higginson, Elasto-hydrodynamic lubrication, SI. Oxford: Pergamon Press, 1977.

[32] C. Roelands, 'Correlational aspects of the viscosity-temperaturepressure relationship of lubricating oils".', Delft University. Delft, 1966.

[33] H. Okamura, 'A contribution to the numerical analysis of isothermal elastohydrodynamic lubrication', in Tribology of Reciprocating Engines, Elsevier, 1993, pp. 313-320.

[34] R. G. Budynas and J. K. Nisbett, Shigley's Mechanical Engineering Design, 9th ed. New York: McGrawHill, 2011.

[35] M. Masjedi and M. M. Khonsari, 'Film Thickness and Asperity Load Formulas for Line-Contact Elastohydrodynamic Lubrication With Provision for Surface Roughness', J. Tribol., vol. 134, no. 1, Jan. 2012.

[36] B. J. Hamrock, 'Film Thickness for Different Regimes of Fluid-Film Lubrication', NASA Technical Memorandum TM-81550. Cleveland, pp. 1-14, 1980. 